\title{
Non-invasive imaging of vascular inflammation
}

\section{Enrico Ammirati ${ }^{1,2}$ *, Francesco Moroni ${ }^{1}$, Patrizia Pedrotti ${ }^{2}$, Isabella Scotti ${ }^{1}$, Marco Magnoni ${ }^{1}$, Enrica P. Bozzolo ${ }^{3}$, Ornella E. Rimoldi ${ }^{1,4}$ and Paolo G. Camici ${ }^{1 *}$}

\author{
${ }^{1}$ Cardiothoracic Department, San Raffaele Scientific Institute and University, Milan, Italy \\ ${ }^{2}$ Cardiovascular and Thoracic Department, AO Ospedale Niguarda Ca' Granda, Milan, Italy \\ ${ }^{3}$ Unit of Medicine and Clinical Immunology, Department of Medicine, San Raffaele Scientific Institute and University, Milan, Italy \\ ${ }^{4}$ CNR Istituto di Bioimmagini e Fisiologia Molecolare, Segrate, Milan, Italy
}

\section{Edited by:}

Augusto Vaglio, University Hospital of Parma, Italy

\section{Reviewed by:}

Patrizia Rovere Querini, Ospedale San Raffaele and Vita-Salute University, Italy

Andrea Vergani, Dompé, USA

\section{*Correspondence:}

Enrico Ammirati, Cardiothoracic

Department, San Raffaele Scientific

Institute and University, Via Olgettina

60, Milan 20132, Italy and AO

Ospedale Niguarda Ca' Granda,

Piazza Ospedale Maggiore 3, Milan

20162, Italy

e-mail:ammirati.enrico@hsr.it;

Paolo G. Camici, Cardiothoracic

Department, San Raffaele Scientific

Institute and University, Via Olgettina

60, Milan 20132, Italy

e-mail: camici.paolo@hsr.it
In large-vessel vasculitides, inflammatory infiltrates may cause thickening of the involved arterial vessel wall leading to progressive stenosis and occlusion. Dilatation, aneurysm formation, and thrombosis may also ensue. Activated macrophages and T lymphocytes are fundamental elements in vascular inflammation. The amount and density of the inflammatory infiltrate is directly linked to local disease activity. Additionally, patients with autoimmune disorders have an increased cardiovascular (CV) risk compared with agematched healthy individuals as a consequence of accelerated atherosclerosis. Molecular imaging techniques targeting activated macrophages, neovascularization, or increased cellular metabolic activity can represent effective means of non-invasive detection of vascular inflammation. In the present review, novel non-invasive imaging tools that have been successfully tested in humans will be presented. These include contrast-enhanced ultrasonography, which allows detection of neovessels within the wall of inflamed arteries; contrast-enhanced $\mathrm{CV}$ magnetic resonance that can detect increased thickness of the arterial wall, usually associated with edema, or mural enhancement using T2 and post-contrast T1-weighted sequences, respectively; and positron emission tomography associated with radio-tracers such as $\left[{ }^{18} \mathrm{~F}\right]$-fluorodeoxyglucose and the new $\left[{ }^{11} \mathrm{C}\right]-\mathrm{PK} 11195$ in combination with computed tomography angiography to detect activated macrophages within the vessel wall. Imaging techniques are useful in the diagnostic work-up of large- and mediumvessel vasculitides, to monitor disease activity and the response to treatments. Finally, molecular imaging targets can provide new clues about the pathogenesis and evolution of immune-mediated disorders involving arterial vessels.

Keywords: vasculitis, non-invasive imaging, contrast-enhanced ultrasound, vascular inflammation, positron emission tomography, cardiovascular magnetic resonance

\section{INTRODUCTION}

Vasculitides are conditions defined by the presence of inflammation of the vessel wall, with progressive alteration of the lumen, including lumen stenosis, occlusion, or even aneurysmal dilation. They can be broadly divided into infectious vasculitides, characterized by direct invasion of pathogens in the vessel wall and non-infectious vasculitides. The latter, also known as primary vasculitides, encompass a heterogeneous group of immune-mediated disorders, classified, according to the size of vessels that are predominantly involved, into small-, medium-, and large-vessel vasculitides (LVV) (1). The diagnosis of small and medium vessels vasculitis is generally based on clinical findings, serological markers, and histological evaluation (2). LVV include giant cell arteritis (GCA), Takayasu arteritis (TAK), primary central nervous system vasculitis (PCNSV), and chronic periaortitis (CP) (3). The most common LVVs are GCA and TAK in which the aorta and its main branches are generally involved. GCA occurs more frequently in older adults, showing a predilection for the temporal artery and other extracranial vessels (4). Clinical manifestation of this disease ranges from ischemic symptoms and signs (such as jaws claudication) to aneurysmal rupture $(4,5)$. TAK is more prevalent in adolescent girls and young women, with a strong predilection for the aortic arch and its branches, in particular the subclavian arteries (up to 98\%) and common carotid, although also pulmonary and coronary arteries $(<10 \%)$ may be involved. The involvement of the major branches of the aorta is much more marked at their origin than distally, leading to clinical manifestations that ranges from arm claudication to myocardial infarction. Different classification criteria for LVV have been defined, and all of them are based upon clinical presentation, evidence of inflammation, and vascular abnormalities (6-8). However, they have proven largely unsatisfactory for diagnostic purposes $(9,10)$, frequently leading to delayed diagnosis (11). Even once the diagnosis is established, accurate monitoring of disease activity and response to therapy is not an easy task (5). Extensive clinical evaluation of the arterial tree is currently recommended (12), and imaging plays a major role in this setting. In vivo detection of inflammation within affected blood vessels may provide a reliable tool to assess disease activity, leading to better clinical management of the patient. Although imaging techniques are particularly useful to diagnose and monitor LVV, they can also play a role in the work-up of medium-vessel vasculitides, classically represented by polyarteritis nodosa (PAN) in 
Table 1 | Features of main non-invasive imaging technique for vascular imaging.

\begin{tabular}{llcc}
\hline Imaging technique & Form of energy & $\begin{array}{l}\text { Spatial } \\
\text { resolution } \\
(\mathbf{m m})\end{array}$ & Availability \\
\hline Ultrasonography & $\begin{array}{l}\text { High frequency sound } \\
\text { waves }\end{array}$ & $0.1-1$ & Widespread \\
$\mathbf{C T}$ & $\mathrm{X}$ rays & $0.3-1$ & Widespread \\
MRI & Radiofrequency & 0.2 & Large centers \\
& waves & & Large centers \\
PET & Photons annihilation & $4-6$ & Largen
\end{tabular}

PET: positron emission tomography; CT: computed tomography; MRI: magnetic resonance imaging.

adults and Kawasaki disease (KD) in children $(13,14)$. In contrast, current imaging techniques are unable to visualize small vessels, thus we will focus on the role of imaging studies in diagnosing and monitoring LVV, including some applications in medium-vessel vasculitides and autoimmune systemic disorders with potential vascular involvement such as Behcet's disease.

Inflammation of the vascular wall is characterized by different pathological changes, such as edema, vasa vasorum activation and proliferation $(15,16)$, alteration of endothelial homeostatic function, and immune cells infiltration $(4,17,18)$, ultimately leading to anatomical remodeling with consequent functional alteration. Knowledge of the biological basis of these processes has led to the development of imaging strategies aimed at identifying them in vivo, mainly with the development of probes directed to key molecular targets (19). Imaging techniques allowing for molecular imaging include ultrasonography, positron emission tomography (PET), most often associated with computed tomography (CT), and magnetic resonance imaging (MRI), all of which will be discussed in this review. Table 1 summarizes the main features of the imaging techniques used to study patients with vasculitides. Furthermore, inflammation of arterial vessels is a fundamental pathogenetic element in atherosclerosis and associated clinical manifestations. Compelling evidence of the link between atherogenesis and inflammation has built over the last decades, leading to the current hypothesis that atherosclerosis is not merely a disease due to passive lipid accumulation in the vascular wall but an active, immune-driven process $(17,18)$. Not surprisingly, many diseases associated with systemic inflammation due to immune alterations are associated with increased risk of cardiovascular (CV) morbidity and mortality due to atherosclerosis $(20,21)$ that cannot be fully explained by traditional CV risk factors, suggesting a role for immune activation (22). Therefore, characterization of inflammation within atherosclerotic plaques by means of molecular imaging may identify patients at risk for disease progression or acute clinical manifestations $(23,24)$.

\section{ULTRASOUND}

Ultrasound imaging is widely available, inexpensive, and repeatable and does not involve the use of ionizing radiation. It is generally performed by an experienced sonographer using highquality Doppler ultrasound equipment and linear probes $>8 \mathrm{MHz}$
$(25,26)$. Examination typically comprises B-mode ultrasonography, which depicts anatomy using a gray scale, and Duplex ultrasound, which combines color Doppler ultrasound and pulsed Doppler ultrasound to display information about blood flow and to estimate blood flow velocities (26). The main limitation of ultrasound imaging is that it cannot depict structures below bone or air. For this reason, it does not provide reliable information about the thoracic aorta, unless performed via a transesophageal approach. In addition, acquisition of ultrasound images is operator dependent, although studies of vascular ultrasound have shown high rates of interoperator agreement $(27,28)$. In the following sections, we will review the main ultrasonographic findings in blood vessel inflammation, which are summarized in Tables 2 and 3 .

\section{COLOR DOPPLER ULTRASOUND}

Schmidt et al. pioneered the use of ultrasonography in LVV. They showed that inflamed temporal arteries in GCA were characterized by a dark hypoechoic circumferential wall thickening dubbed the halo sign, which appeared to be edema of the vessel (29). The investigators reported a sensitivity of $73 \%$ and a specificity of nearly $100 \%$. Subsequently, temporal artery ultrasonography has increasingly been used to screen patients with suspected GCA. An early meta-analysis showed a sensitivity of $69 \%$ and a specificity of $82 \%$ for the halo sign using temporal artery biopsy as the reference standard (30). Subsequent meta-analysis showed a sensitivity of $69 \%$ and a specificity of $91 \%$ (31), and a sensitivity of $69 \%$ and a specificity of $89 \%$ (32), respectively, when American College of Rheumatology (ACR) criteria were used as reference standard. Interestingly, specificity increased to $100 \%$ when presence of the halo sign was bilateral (31). As expected, the quality of the equipment used to perform the examination as well as operator experience was shown to affect diagnostic power of the halo sign (30-32). The halo sign can also be found in inflamed large vessels, which have been shown to be involved in approximately one-third of patients affected by GCA $(33,34)$. Detection of the halo sign in large vessels further increases ultrasound sensitivity to nearly $100 \%(35,36)$. The equivalent of the halo sign in TAK is called the macaroni sign, a circumferential midechoic thickening of the blood vessel wall (37). Both of these echographic findings have been shown to fade and disappear after initiation of steroid therapy during patients follow-up (38-40). Aside from edema, ultrasound evaluation of the vessel wall may show other vascular alterations. Evaluation of carotid artery wall thickness, i.e., carotid artery intima-media thickness (CIMT), in particular has proved a reliable surrogate measure of atherosclerotic burden and CV risk in the general population (41). CIMT (Figure 1) was shown to be significantly increased in patient affected by a variety of rheumatic diseases: this may represent the result of a multifactorial process in which age and other traditional CV risk factors (i.e., systolic blood pressure, low-density lipoprotein (LDL), cholesterol levels, and body mass index) make a continuous contribution, and interact with inflammation and immunological factors $(42,43)$. Clear depiction of blood vessel lumen allows detection of stenosis or aneurysmal dilation, which appear as alterations in wall profile as well as flow abnormalities, making ultrasound a valuable tool for monitoring vasculitides complications (3). 
Table 2 | Summary of main ultrasonographic findings in inflamed blood vessel, together with their pathological correlate and clinical significance.

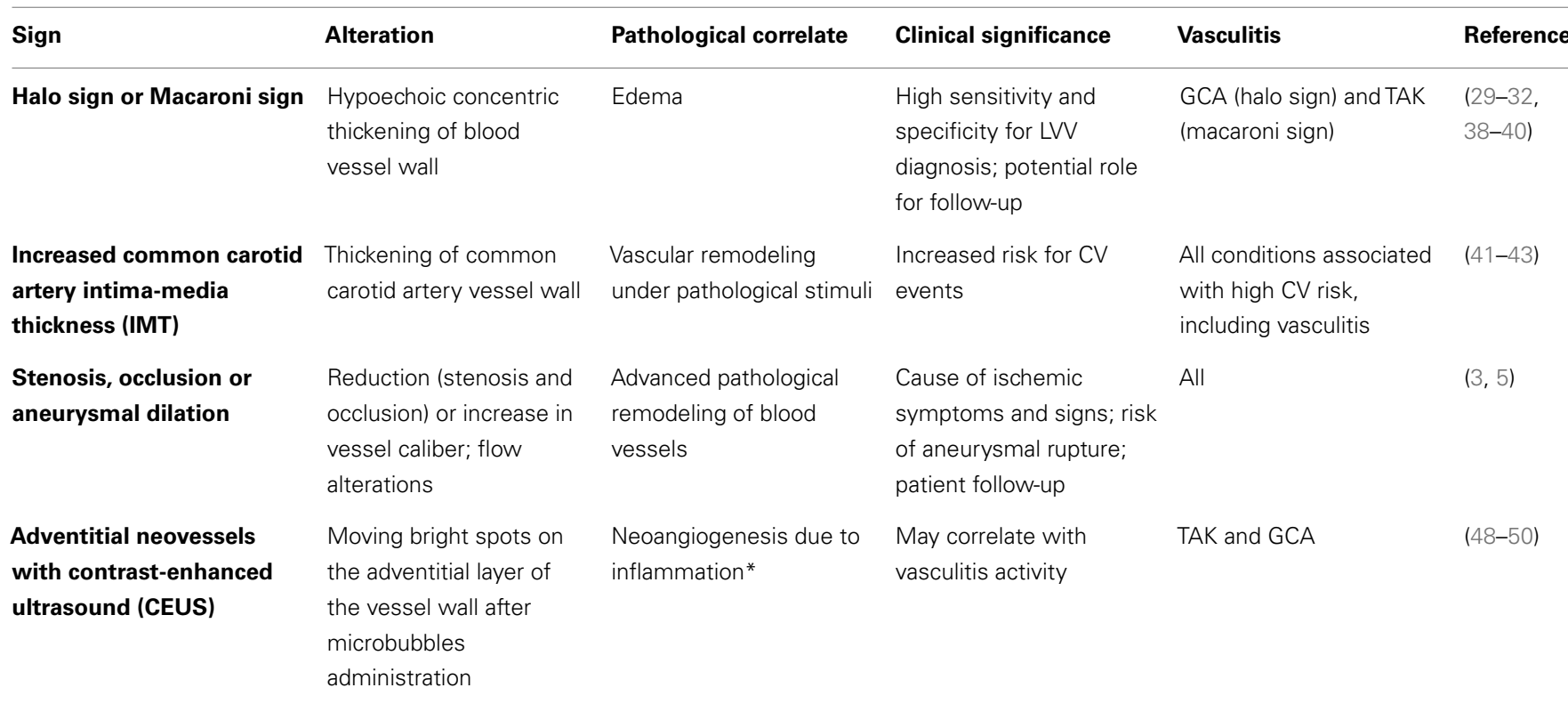

${ }^{*}$ Correlation with neovessel formation has been demonstrated for atherosclerosis. Pathological correlation studies for vasculitides have not yet been performed.

\section{CONTRAST-ENHANCED ULTRASOUND}

Several different formulations of ultrasound contrast agents exist. They share the feature of being micro or nano sized, gas-filled particles, known as microbubbles, which remain in the vascular compartment. They generate a hyperechogenic signal because they resonate, i.e., cyclically expand and contract, or release gas when insonated at frequencies used by ultrasound imaging systems (44). When applied to vascular imaging, contrast-enhanced ultrasound (CEUS) is able to enhance the lumen, improving delineation of blood vessel wall (45). In addition, microbubbles allow detection of adventitial neovessels (46), which is a potential marker for atherosclerotic plaque instability (47). Recently, CEUS has been proposed as a potentially useful imaging modality in assessing disease activity in LVV. In early reports by Giordana et al. (48) and Magnoni et al. (49), carotid CEUS was used to diagnose TAK and monitor response to treatment. The authors initially observed circumferential wall thickening in the common carotid artery with multiple vasa vasorum. After treatment, carotid CEUS was repeated and showed progressive reduction in vessel wall and vasa vasorum enhancement, suggesting decrease of inflammatory activity in the carotid artery. CEUS improved definition of borders of the vascular lesion and demonstrated the presence of large amount of contrast, visualized by moving bright spots, on the adventitial side of vascular lesions (Figures 2A,B). The latter phenomenon was interpreted as a signal coming from neovessels. More recently, Schinkel et al. (50) confirmed these results in a pilot study involving seven patients, of which five were affected by TAK and two by GCA. They showed that CEUS significantly improved image quality as compared to standard color Doppler ultrasound and allowed detection of vascularization in carotid vessel wall. CEUS can be employed for molecular imaging (51, 52); unlike freely circulating microbubbles used for vascular opacification, targeted microbubbles are designed to adhere to the endothelium through specific interactions. The adhesion is then detected as increase in echogenicity, which persists after circulating bubbles have been washed away in the site where molecular target is localized. Examples of targets successfully visualized in preclinical experimental models with molecular targeted CEUS include leukocyte adhesion molecules including ICAM-1, VCAM-1, and P-selectin. In the future, this technology will provide the possibility of directly visualizing pathophysiologic events, including inflammatory changes, occurring in the patient's blood vessels.

The fact that proliferation of vasa vasorum and intimal neovascularization may play a role in atherosclerosis was clearly shown by postmortem studies by Barger et al. (53), who showed that atherosclerotic segments of coronary arteries present a rich vascular network extending from the adventitia to the intima. Atherosclerotic plaque neovascularization may contribute to the progression of a fibrotic, stable lesion to an unstable lesion at high risk of rupture $(47,54)$. Visualization of intra-plaque neovascularization may therefore provide a way to identify high risk, vulnerable plaques. Detection of blood vessel wall enhancement by CEUS was shown to correlate well with histological evidence of plaque neovascularization, as defined by presence of CD31 positive cells $(46,55)$. This technique may thus have a relevant future role in risk assessment of atherosclerotic plaques also in patients with immune-mediated disorders.

\section{TRANSESOPHAGEAL ECHOCARDIOGRAPHY}

Transesophageal echocardiography (TEE) is a semi-invasive ultrasound imaging technique that allows high-quality evaluation of the heart and the aortic root. The exam is carried out using an ultrasonographic transducer mounted on the tip of a modified steerable gastroscope inserted in the esophagus (56). This 
Table 3 | Summarizes key studies concerned with imaging of inflammation in blood vessels in LVV, and their main results.

\begin{tabular}{|c|c|c|c|c|}
\hline Technique & Study & $\begin{array}{l}\text { Number of } \\
\text { patients }\end{array}$ & Results & Reference \\
\hline \multirow[t]{4}{*}{ Color Doppler ultrasound } & $\begin{array}{l}\text { Ball et al., The British Journal of Surgery, } \\
2010\end{array}$ & 998 & $\begin{array}{l}\text { Meta-analysis of } 17 \text { studies showing a } \\
\text { sensitivity of } 69 \% \text { and a specificity of } \\
89 \% \text { for the halo sign in temporal artery }\end{array}$ & $(32)$ \\
\hline & $\begin{array}{l}\text { Arida et al., BMC Muscoloskeletal } \\
\text { Disorders, } 2010\end{array}$ & 504 & $\begin{array}{l}\text { Meta-analysis of } 8 \text { studies showing a } \\
\text { sensitivity of } 68 \% \text { and a specificity of } \\
91 \% \text { for the halo sign in temporal artery }\end{array}$ & (31) \\
\hline & Maeda et al., Ultrasound Med Mol, 1991 & 23 & $\begin{array}{l}\text { "Macaroni" sign detected carotid artery } \\
\text { involvement in } 19 \text { out of } 23 \text { patients with } \\
\text { TAK }\end{array}$ & (37) \\
\hline & Habib et al., Clin Rheumatol, 2012 & 32 & $\begin{array}{l}\text { Halo sign decreases after a mean of } \\
21 \text { days from beginning of therapy }\end{array}$ & (39) \\
\hline \multirow[t]{2}{*}{ Transesophageal ultrasound } & $\begin{array}{l}\text { Bezerra Lira-Filho et al., Journal of the } \\
\text { American Society of Echocardiography, } \\
2006\end{array}$ & 14 & $\begin{array}{l}71 \% \text { of thoracic aorta segments were } \\
\text { found to be thickened, and } 37 \% \text { dilated in } \\
\text { the } 14 \text { TAK patients studied by } \\
\text { transesophageal echocardiography }\end{array}$ & $(60)$ \\
\hline & $\begin{array}{l}\text { Espinola-Zavaleta et al., Echocardiography } \\
\text { (Mount Kisco, NY). } 2005\end{array}$ & 15 & $\begin{array}{l}\text { In the studied TAK patient cohort, } 67 \% \text { of } \\
\text { patients had aortic regurgitation, } 60 \% \\
\text { mitral or tricuspid regurgitation and } 33 \% \\
\text { reduced coronary reserve measured with } \\
\text { contrast enhancement }\end{array}$ & (61) \\
\hline & Kang et al., Radiology, 2014 & 111 & $\begin{array}{l}53 \% \text { of patients had coronary artery } \\
\text { involvement, while only } 29 \% \text { were } \\
\text { symptomatic for heart disease }\end{array}$ & $(72)$ \\
\hline \multirow[t]{3}{*}{ PET using FDG } & $\begin{array}{l}\text { Besson et al., European Journal of Nuclear } \\
\text { Medicine and Molecular Imaging, } 2011\end{array}$ & 101 & $\begin{array}{l}\text { Meta-analysis of six studies on patients } \\
\text { with GCA, showing a sensitivity of } 80 \% \\
\text { and a specificity of } 89 \% \text { for FDG-PET }\end{array}$ & $(81)$ \\
\hline & $\begin{array}{l}\text { Blockmans et al., Arthritis and } \\
\text { Rheumatism, } 2006\end{array}$ & 35 & $\begin{array}{l}\text { Vascular FDG uptake was shown in } 83 \% \\
\text { of } 35 \text { patients with GCA. It decreased } \\
\text { after } 3 \text { months of effective therapy, but no } \\
\text { further decrease was documented at } \\
6 \text { months follow-up }\end{array}$ & (88) \\
\hline & $\begin{array}{l}\text { Fuchs et al., European Journal of Nuclear } \\
\text { Medicine and Molecular Imaging, } 2012\end{array}$ & 30 & $\begin{array}{l}\text { PET was shown to increase diagnostic } \\
\text { accuracy for LVV from } 54 \text { to } 71 \%\end{array}$ & $(87)$ \\
\hline
\end{tabular}


Table 3 | Continued

\begin{tabular}{|c|c|c|c|c|}
\hline Technique & Study & $\begin{array}{l}\text { Number of } \\
\text { patients }\end{array}$ & Results & Reference \\
\hline PET with PK11195 & $\begin{array}{l}\text { Pugliese et al., Journal of the American } \\
\text { College of Cardiology, } 2010\end{array}$ & 15 & $\begin{array}{l}\text { PET/CT allowed visualization of tracer } \\
\text { uptake in the vessels of all the six } \\
\text { patients with active disease, but in none } \\
\text { of the controls }\end{array}$ & $(96)$ \\
\hline \multirow[t]{5}{*}{$\begin{array}{l}\text { Magnetic Resonance } \\
\text { Imaging }\end{array}$} & Mavrogeni, J Am Coll Cardiol, 2004 & 13 & $\begin{array}{l}\text { Agreement between bright-blood MRI } \\
\text { angiography and coronary X-ray } \\
\text { angiography in identifying coronary } \\
\text { aneurysms in KD }\end{array}$ & $(106)$ \\
\hline & Comarmond, Am J Cardiol, 2014 & 27 & $\begin{array}{l}\text { Myocardial ischemia detected by LGE at } \\
\text { CMR was }>5 \times \text { greater in patients with } \\
\text { TA compared to matched controls }\end{array}$ & $(133)$ \\
\hline & Li, J Comput Assist Tomogr, 2011 & 42 & $\begin{array}{l}\text { Whole body MRI; wall thickness and } \\
\text { post-contrast signal higher in TAK patients } \\
\text { with active disease }\end{array}$ & $(134)$ \\
\hline & $\begin{array}{l}\text { Koenigkam-Santos, J Clin Rheumatol, } \\
2011\end{array}$ & 28 & $\begin{array}{l}\text { GCA/polymyalgia rheumatica; CE-MRA } \\
\text { identified extracranial involvement with } \\
\text { good interobserver agreement }\end{array}$ & $(135)$ \\
\hline & $\begin{array}{l}\text { Mavrogeni, Inflamm Allergy Drug Targets, } \\
2013\end{array}$ & 28 & $\begin{array}{l}\text { CMR in Churg-Strauss syndrome showed } \\
\text { cardiac involvement, with worse } \\
\text { prognosis in presence of diffuse } \\
\text { sub-endocardial fibrosis }\end{array}$ & $(136)$ \\
\hline
\end{tabular}

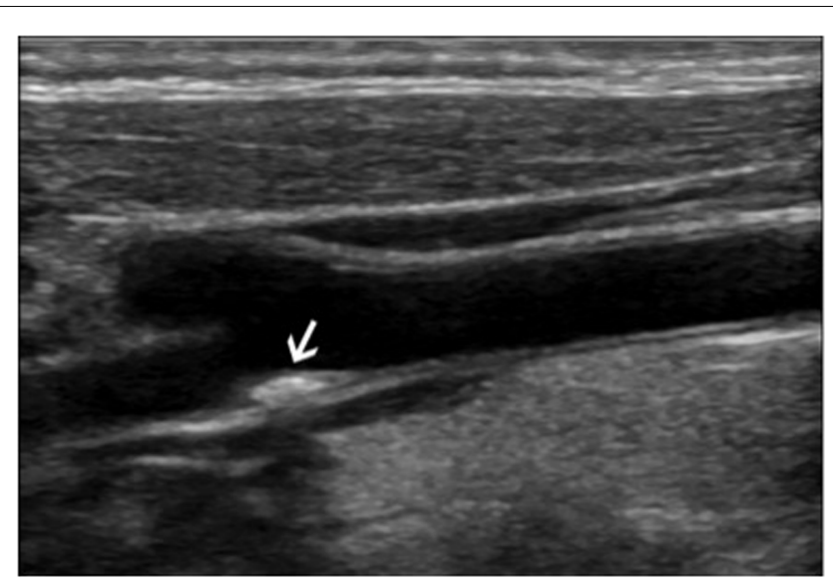

FIGURE 1 | Ultrasound imaging of the right carotid artery bifurcation of a 44-year-old woman with a 10 years history of systemic lupus erythematosus: the arrows show an atherosclerotic plaque extending toward the internal carotid artery.

technique allows correct identification of eventual thoracic aorta and coronary arteries involvement in LVV. Although several reports of utilization of TEE in the evaluation of LVV, especially in the setting of perioperative evaluation (57-59), few clinical studies have been performed using this technique. Bezerra Lira-Filho and colleagues described the most common lesions in 14 patients affected by TAK compared with age-matched controls: aortas of the patients were found to be thicker, more dilated, and stiffer as compared with controls (60). In another study, Espinola-Zavaleta et al. assessed coronary reserve in 15 patients with TAK using contrast-enhanced TEE: $33 \%$ of the patients were found to have reduced coronary reserve, while aortic and mitral valve regurgitation was found in $67 \%$ and $60 \%$, respectively (61). CEUS can also improve the TEE (62).

\section{CT AND CT ANGIOGRAPHY}

Computed tomography is well suited to demonstrate pathological changes in large, deep blood vessels. While it is a widely available and reproducible technique, it involves the use of ionizing radiation and carries a risk connected to the use of iodinated contrast material although radiation dose to the patient has declined steadily in the past few years due to different technological advances (63). CT angiography is able to show alterations both in the wall and in the lumen of affected vessel in LVV (64). In early vasculitis, concentric mural thickening of the involved arteries is typically observed $(65,66)$. On pre-contrast scanning, the mural thickening has a higher attenuation as compared to the lumen, while in enhanced images it displays a double ring enhancement pattern, most evident in the venous phase (67). In particular, the wall shows a poorly enhanced inner ring and a more obviously enhanced outer ring; it has been proposed that the inner ring represents a swollen intima while the outer one represents active inflammation in the intima and in the media $(67,68)$. Mural enhancement usually resolves after successful treatment, 

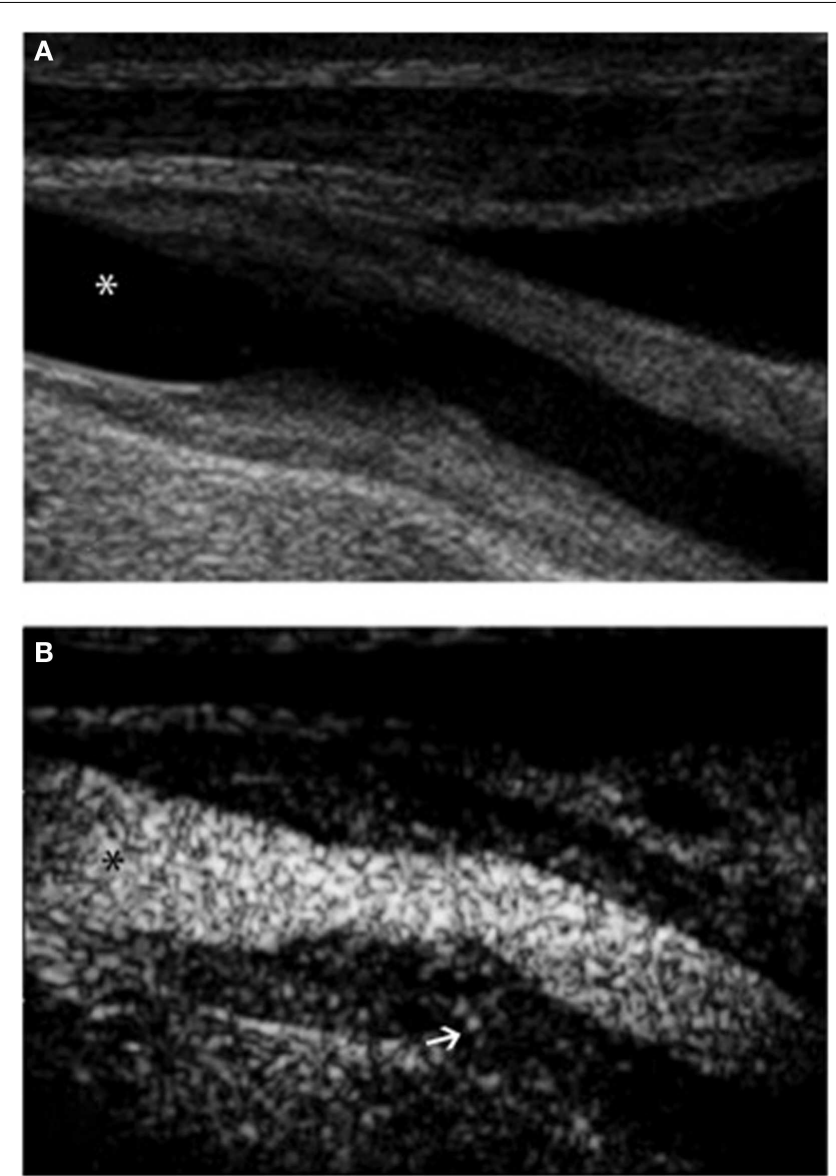

FIGURE 2 | Ultrasound examination of right proximal common carotid artery of a patient affected by Takayasu arteritis. B-mode ultrasound (A) shows long, smooth concentric thickening of the arterial wall.

Contrast-enhanced ultrasound (B) using Optison (GE Healthcare, Little Chalfont, UK), a contrast media made up of human albumin microbubbles filled with perflutren, improves definition of the lesion border. Extensive enhancement can be seen within the vessel wall (arrow). In both panels, asterisk marks the vessel lumen.

although its improvement may lag behind clinical and laboratory improvement $(69,70)$. In advanced disease, CT angiography shows typical late stage complications such as aneurysms, vessel stenosis, or occlusion (66) (Figure 3). Compared with conventional angiography, CT was able to accurately assess stenotic lesions in brachiocephalic trunks, carotid arteries, and subclavian arteries in patients with TAK, with a sensitivity and specificity of 93\% and $98 \%$, respectively (71). In addition, coronary arteries assessment with CT was able to show coronary artery lesions in 53\% of 111 TAK patients, while only $29 \%$ had cardiac symptoms (72). The most common lesions were ostial stenosis, non-ostial stenosis, and coronary aneurysms. In another study, CT was able to detect large-vessel involvement in 27 of 40 patients affected by GCA (73).

\section{PET AND PET/CT}

Imaging with PET offers unrivaled sensitivity and specificity for research into tissue perfusion, biochemical pathways, and pharmacological mechanisms in vivo. The success of PET is founded on the properties of positron emitters. Their short physical half-lives

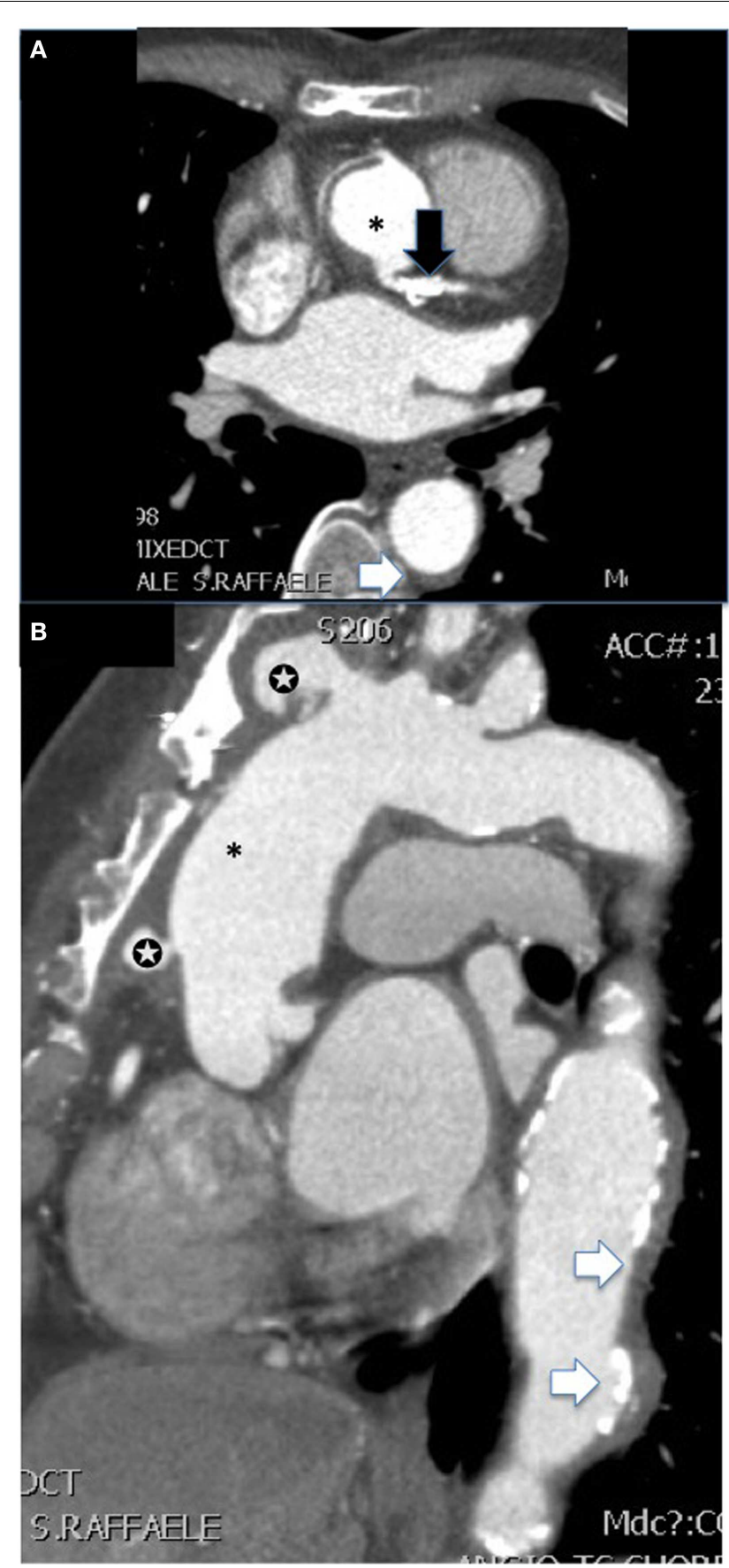

FIGURE 3 | CT angiography [(A) shows axial and (B) sagittal view] of the aorta of a female patient with advanced Takayasu arteritis who underwent previous surgical repair of an ascending aorta aneurysm $\left.{ }^{*}\right)$. Several features of the disease are summarized in these images: post-surgical complications such as pseudoaneurysms at the level of proximal and distal anastomosis of the vascular graft with the native aorta (white stars), extensive concentric mural thickening with calcifications of the aorta (white arrows), and presence of a stent in the main steam with a calcific stenosis (black arrow)

make it possible to administer a tracer dose high enough to obtain useful data, but such that the radiation burden to the patient is acceptably low. A tracer is a measurable substance used to mimic, 

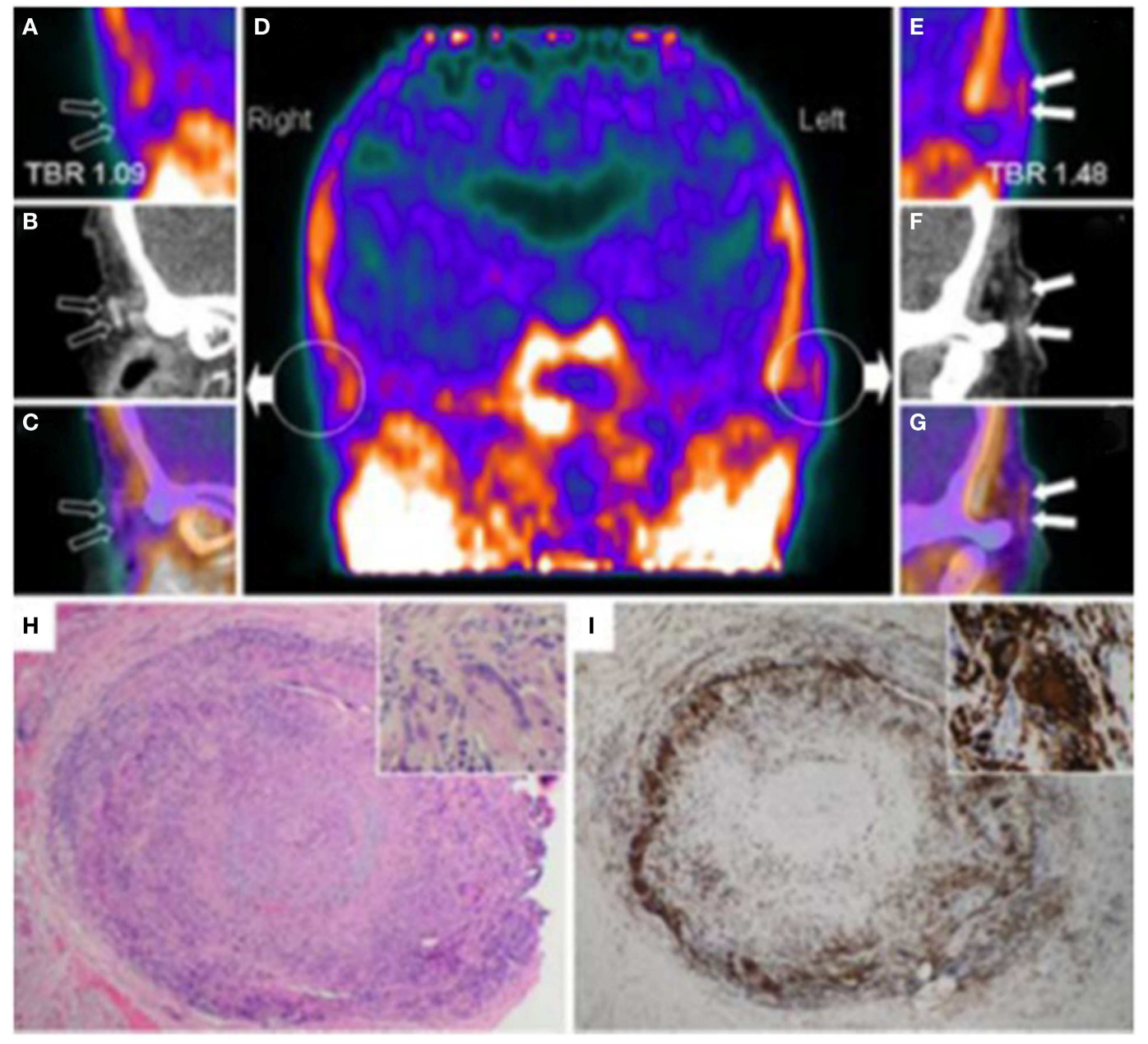

FIGURE 4 | Hybrid PET with PK11195 and CT angiography imaging of an 88-year-old woman presenting with left scalp tenderness, jaw claudication, and night sweats. The coronal reconstruction (D) and magnifications of PET $(\mathbf{A}, \mathbf{E})$, and contrast-enhanced CT $(\mathbf{B}, \mathbf{F})$ and PET/CT fusion images $(\mathbf{C}, \mathbf{G})$ show focal PK11195 uptake in the left temporal artery above the zygomatic process (solid arrows) compared to the contralateral artery (open arrows). The arterial target-to-background ratio (TBR) was higher in the left than in the right temporal artery. On CT angiography, the left temporal artery lumen $(1.8 \mathrm{~mm}$ diameter) was irregular with reduced contrast opacification compared with the contralateral $(2.2 \mathrm{~mm}$ diameter).

follow or trace a chemical compound or process without disturbing the process under study. In the case of PET, this is made possible by: (1) the high sensitivity of PET imaging which enables the measurement of radiolabeled tracers administered in picomolar concentrations, which are sufficiently low so as not to disturb the processes under study; and (2) the ability of current PET scanners to perform rapid dynamic imaging and/or list mode acquisitions that provide good temporal resolution. Although it shows great sensitivity to even small amounts of probe mass, PET has a relatively poor spatial resolution (23), compared to CT and MRI. For this reason, coregistration of PET images with contrasted CT images has been developed, to provide good anatomical localization of functional data (74). Using this technique, Gaemperli et al.
The H\&E biopsy specimen $(\mathbf{H})$ of the left temporal artery $(4 \times$ objective $)$ shows transmural granulomatous infiltration (containing activated lymphocytes, macrophages, and multinucleated giant cells), secondary myofibroblast proliferation, and significant intimal thickening leading to luminal obliteration. Large part of the media and the internal elastic lamina are destroyed. The inset (H\&E, $\times 100$ objective) demonstrates a multinucleated giant cell. CD68 (macrophage marker, shown in panel I) staining brown with immunoperoxidase ( $\times 4$ objective) shows dense macrophage infiltration with multinucleated cells (inset, $\times 100$ objective). [adapted with permission from Springer] first reported detection of temporal artery inflammation using PET in a patient with GCA (Figure 4) (75).

\section{PET AND PET CT USING FDG}

[18F]-fluorodeoxyglucose (FDG) is a radiolabeled glucose analog, which competes with glucose for transport across the sarcolemma and phosphorylation by hexokinase and is avidly accumulated by metabolically active cells. Currently, PET imaging with FDG plays a major role in the management of cancer patients (76). Activated inflammatory cells also overexpress glucose transporters and extract increased amounts of glucose and hence FDG (77). In large-vessel vasculitides, FDG uptake in the vascular wall is increased. The uptake is commonly classified on a four-point 


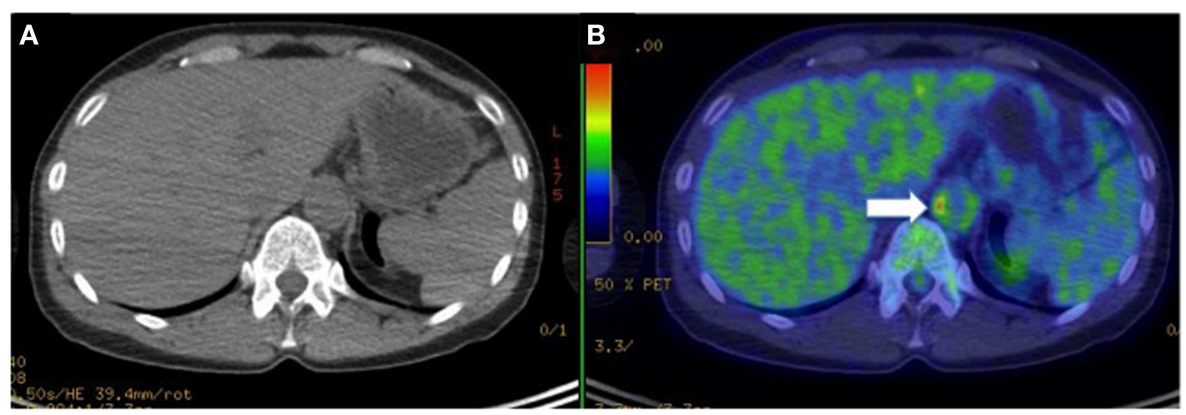

FIGURE 5 | Hybrid CT (A) with PET imaging (B) to identifies $\left[{ }^{18} \mathrm{~F}\right]$-fluorodeoxyglucose (FDG) accumulation in the vascular wall of abdominal aorta (arrow) in a female patient with Takayasu arteritis.

visual grading system: no uptake (grade 0 ), less than liver uptake (grade 1), uptake similar to that of the liver (grade 2), and uptake higher than the liver (grade 3) (78). Grades 2 and 3 appear to be specific for vasculitis (79). Alternatively, the semi-quantitative aorta to liver ratio proposed by Hautzel et al. provides an excellent global performance for the diagnosis of GCA, with a sensitivity of $89 \%$ and a specificity of $96 \%$, together as robustness as an observer-independent method (80). According to a recent metaanalysis, FDG-PET has a sensitivity of $80 \%$ and a specificity of $89 \%$ in the diagnosis of GCA, using ACR criteria as reference standard (81). FDG-PET was also shown to be useful in early diagnosis of TAK, showing a sensitivity ranging from 65 to $100 \%$ and high specificity $(82,83)$. Combination of PET with CT imaging was shown to increase diagnostic yield for LVV, allowing for better visualization of tracer accumulation in the vascular wall $(84,85)$ (see Figure $\mathbf{5}$ as an example of female patients with inflammation localized at the abdominal aortic wall identified by accumulation of FDG) and visualization of small diameter arteries such as temporal artery (86). Diagnostic accuracy of FDG-PET dramatically decreases after initiation of appropriate therapy (87), providing a valuable tool for disease monitoring $(88,89)$. Furthermore, PET was shown to reliably predict GCA complications, e.g., aortic dilation (90), but it was unable to identify patient at higher risk of relapse (88). A recent study formally assessed the impact of FDGPET on the diagnosis of LVV (87). A panel of international experts was asked to diagnose and manage patients with suspect LVV either with or without having access to PET results: PET was shown to significantly increase diagnostic accuracy from 54 to $71 \%$.

\section{PET/CT USING [11 C]-PK11195}

[N-methyl- $\left.{ }^{11} \mathrm{C}\right]-(\mathrm{R})-1-(2-$ chlorophenyl)- $N$-(1-methylpropil)-3isoquinoline carboxamide, also known as [ $\left.{ }^{11} \mathrm{C}\right]-\mathrm{PK} 11195$, is a radiolabeled ligand that specifically binds to the translocator protein (TSPO, $18 \mathrm{kDa}$ ), formerly known as peripheral benzodiazepine receptor (91). TSPO has been shown to be present at high density in circulating human phagocyte populations, in particular in monocytes and neutrophils (92). Stimulated human monocytes further increase TSPO expression, indicating that its overexpression associates with activation of phagocytes (93). Over the last two decades, $\left[{ }^{11} \mathrm{C}\right]-\mathrm{PK} 11195$ has been extensively used in a number of neuroinflammatory and neurodegenerative conditions due to its high uptake in activated microglia and low uptake in neurons (94). Subsequent reports have demonstrated $\left[{ }^{11} \mathrm{C}\right]-\mathrm{PK} 11195$ uptake in synovial macrophages of patients affected by rheumatoid arthritis (95). Pugliese et al. first applied $\left[{ }^{11} \mathrm{C}\right]-\mathrm{PK} 11195$ in LVV imaging in a small, proof-of-principle study involving 15 patients, predominantly affected by TAK and GCA (96). In this study, all five patients with clinically active vasculitis had markedly increased vascular uptake of the tracer as compared with patients with quiescent disease. Standardized uptake values for $\left[{ }^{11} \mathrm{C}\right]-\mathrm{PK} 11195$ correlated well with quantitative total intra-plaque volumes of distribution, calculated from dynamic tissue kinetic modeling using a onetissue compartment model (97). In one patient, PET/CT images were obtained after a 20 -week course of oral corticosteroids: vascular uptake of $\left[{ }^{11} \mathrm{C}\right]-\mathrm{PK} 11195$ was markedly reduced, and the reduction was paralleled by clinical improvement and decrease in biochemical markers of inflammation (96). The estimated effective dose for CT was $6.0 \pm 0.5 \mathrm{mSv}$ and $2.1 \pm 0.2 \mathrm{mSv}$ for PET scan and the mean total effective dose was $8.1 \pm 0.6 \mathrm{mSv}$ (96). These values are comparable to those of a cardiac FDG scan (98). Finally, $\left[{ }^{11} \mathrm{C}\right]-\mathrm{PK} 11195$ uptake was found to correlate with presence of inflammatory cells in atherosclerotic plaque specimens obtained by carotid artery endarterectomy (99). In the same study, carotid uptake of the radiotracer was higher in patients who had suffered from ischemic stroke, suggesting that this technique may be useful in detecting unstable high-risk plaque $(24,99)$. Despite these promising results, widespread use of $\left[{ }^{11} \mathrm{C}\right]-\mathrm{PK} 11195$ may be limited by its short physical half-life $(20 \mathrm{~min})$, which mandates an on-site cyclotron facility. New ${ }^{18}$ F-labeled TSPO ligands, now undergoing preclinical investigation, may overcome some of these barriers (100).

\section{MAGNETIC RESONANCE IMAGING}

Magnetic resonance imaging is increasingly recognized as a valuable tool in the work-up of patients affected by large- and mediumsized arteries vasculitis (101). MRI has the advantage of avoiding radiations and nephrotoxic contrast medium, while allowing a high-resolution characterization of both vessel wall and lumen. Moreover, systemic vasculitis is increasingly being linked to the occurrence of heart failure secondary to myocardial damage and cardiac magnetic resonance (CMR) has proven to be a refined diagnostic procedure to evaluate both cardiac function and myocardial 


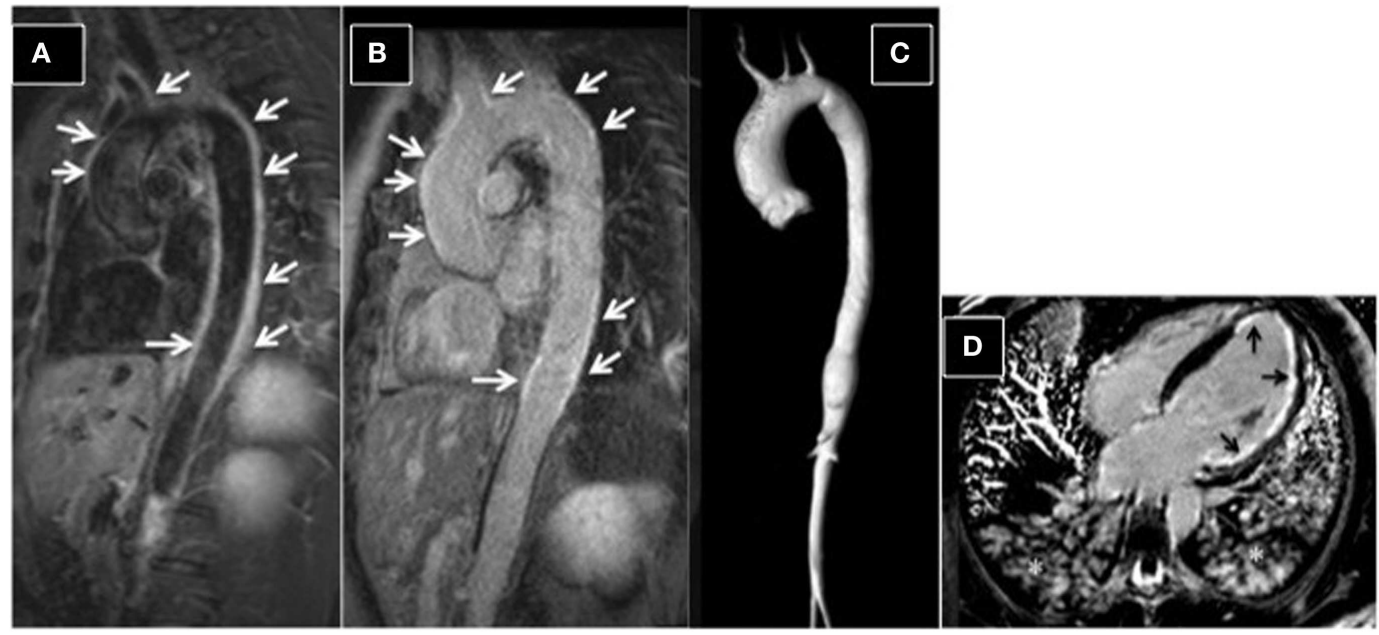

FIGURE 6 | Aortitis in Behcet's disease. (A) STIR T2 dark-blood imaging showing extensive edema of the aortic wall (arrows). Post-contrast late-enhancement imaging (B) shows extensive enhancement of the aortic wall (arrows). A typical Takayasu aortitis presenting with cardiac arrest and acute myocardial infarction in a 16-year-old girl. (C) 3D-MRA reconstructed image, showing dilation of the ascending aorta and narrowing of the descending aorta.

(D) Post-contrast four-chamber view, showing extensive sub-endocardia and focally nearly transmural myocardial late enhancement (ischemic late-enhancement pattern) of the apical and lateral left ventricular walls. Asterisks highlight the presence of pulmonary edema; the patient was intubated during the scan. tissue characterization (102). Avoidance of radiations and tissue characterization capability render MRI an ideal tool not only in defining diagnosis and disease extension but also in evaluating response to treatment and in follow-up. One of the strengths of MRI is the capability of tissue characterization even in basal conditions, before the administration of contrast, so a typical scan includes a pre- and a post-contrast phase; in patients in whom a cardiac examination is also performed, these two steps pertain also to heart evaluation.

\section{PRE-CONTRAST MRI TECHNIQUES}

1. Dark-blood morphologic images (HASTE; T1 or T2 turbo spin-echo images), acquired in the axial, sagittal, and coronal planes); in these images blood appears black, while the vessel wall is clearly depicted and its characteristics, such as thickness and regularity can be easily ascertained. Short-tau inversionrecovery images (STIR images) are dark-blood T2-weighted images in which the signal of fat is saturated and that allow the identification of tissue edema (103). This sequence is particularly useful to identify vessel wall active inflammation with edema in the acute phase and to monitor response to therapy and disease activity during follow-up (Figure 6A).

2. Bright-blood morphologic images (single-shot true-FISP images) in which blood appears bright and that allow the evaluation of vessel wall characteristics.

3. Non-contrast angiography. Time of flight angiography (TOF) is the most frequently non-contrast angiography used, especially to study intracranial and peripheral vessels. This technique can be exploited in patients in whom contrast administration is contraindicated (104). The presence of slow flow or vessel tortuosity can impair image quality and represent a limitation of this technique. Bright-blood whole-heart, self-navigated MRI allowing free-breathing is a technique steadily being improved to acquire $3 \mathrm{D}$ images of the aorta and coronary arteries without the need of contrast $(104,105)$. Techniques allowing the evaluation of coronary arteries are particularly useful when these vessels are involved. Mavrogeni et al. demonstrated complete agreement between bright-blood MRI angiography and coronary X-ray angiography in identifying coronary aneurysms in patients affected by KD (106). The avoidance of X-ray exposure is particularly advantageous in this young population and renders MRI the ideal tool for follow-up. Moreover, adding a complete cardiac evaluation with CMR allows a comprehensive evaluation of both the coronary tree and heart muscle (107).

\section{POST-CONTRAST MRI TECHNIQUES}

Three-dimensional (3D) contrast-enhanced magnetic resonance angiography (CE-MRA) is the corner stone for vessel lumen evaluation with high-spatial resolution (Figure 6C). At higher strength fields (3 T), an improvement in spatial resolution can be obtained with lower contrast dosage (104). Post-contrast acquisitions include T1-weighted images (e.g., VIBE) targeted at the evaluation of vessel wall, allowing the identification of thickening and thrombus stratification and late-enhancement images, obtained with the inversion-recovery technique, showing contrast accumulation (the so-called "late enhancement") in pathologic vessel walls (Figure 6B).

\section{CARDIAC EVALUATION WITH CMR}

Systemic vasculitidies can affect the heart either directly, through vasculitis-related myocarditis or indirectly, through myocardial ischemia secondary to coronary artery involvement $(102,108)$. CMR allows the evaluation of cardiac volumes and function through cine images, the assessment of valvular function with 
phase-contrast images and the detection of myocardial edema, secondary to inflammation or ischemia through STIR T2-images. Post-contrast images obtained with the inversion-recovery technique highlight pathologic areas of contrast accumulation in the myocardium, identifying scar (Figure 6D). CMR is the ideal tool also to follow-up patients with cardiac involvement, to monitor response to therapy and disease activity.

\section{IMAGING AND BIOMARKERS}

The measurement of acute phase reactant, i.e., C-reactive protein (CRP) and erythrocyte sedimentation rate (ESR), is currently recommended for LVV patients follow-up (12) and undoubtedly provides a useful aid for many patients. However, it is established that vascular inflammation and disease progression can occur in the face of normal levels of CRP or ESR, or both $(109,110)$. In addition, critical analysis of the utility of CRP and ESR, alongside other proposed biomarkers of disease activity in TAK, including soluble adhesion molecules and von Willeband factor, showed that they do not reliably identify active disease (111). The need for more effective markers has prompted the evaluation of several different new molecules, among which Pentraxin 3 (PTX3) deserves a special mention. PTX3 is a member of the pentraxin's superfamily and is induced by different cell types, including endothelial cells, smooth muscle cells, and mesangial cells upon inflammatory stimulation (112). Dagna et al. first reported that plasma levels of PTX3 were higher in patients with active TAK as compared with patients with inactive disease, and that TAK patients had higher PTX3 plasma concentration than healthy controls and subjects suffering from acute infections (113). Subsequent reports showed high sensitivity and specificity, 82 and 77\%, respectively, of PTX3 for the detection of active disease $(114,115)$, suggesting that it may be of help in early detection of disease recurrence. Monitoring of LVVs by means of biomarkers, however, currently appears to be suboptimal and not fully reliable.

To the best of our knowledge, no systematic study has been performed to assess a correlation between serum level of biomarkers and imaging findings of inflammation. However, many studies report a lack of association between serum levels of CRP and ESR and imaging evidence of active inflammation during follow-up. In particular, a general trend toward persistence of low-grade positive imaging after normalization of acute phase reactants after initiation of treatment is shown for ultrasound $(34,116)$, FDGPET (88) and MRI (117). Furthermore, a study performed with PK11195-PET showed that this imaging modality was more effective in identifying clinically active LVV than evaluation of ESR and CRP (96). While none of these findings appears to be conclusive, it is arguable that imaging may be more effective than currently available routine serological biomarkers in the assessment of LVV activity, and may provide an effective means of identifying subclinical active disease.

\section{CONCLUSIVE CLINICAL REMARKS}

Clinical evaluation still plays a major role in the diagnosis of LVV, also considering the fact that classification criteria have not yet been revised in response to the increased sensitivity of noninvasive imaging techniques (5). The likelihood of early diagnosis, which would be desirable in order to prevent irreversible vascular damage, is not facilitated by the protean manifestation of the diseases, and by the lack of constitutional symptoms in up to $50 \%$ of patients $(118,119)$. The index of suspicion should be held high for patients with unexplained acute phase response, hypertension, or symptoms of ischemia, and should trigger the request for non-invasive imaging $(2,5,12)$. Although an early report questioned its utility in the evaluation of LVV (120), imaging of superficial vessels by color Doppler ultrasound was subsequently shown to have a good sensitivity and specificity for the diagnosis of these diseases $(31,32)$. Changes in ultrasonographic findings have been reported after initiation of an effective therapy (3840, 121): alongside low economical and biological cost, this makes color Doppler ultrasound a suitable technique for patients' followup. CEUS may further enhance diagnostic power and role in the follow-up of the disease, but evidence is still lacking to warrant its use in clinical practice. For those patients in whom ultrasound examination is negative, PET scanning with FDG is the logical second-line approach. This technique has been shown to greatly increase diagnostic accuracy for LVV (87), and may be particularly useful for those patients with atypical presentation, in which LVV is only one of the several possibilities $(122,123)$. Although FDG uptake decreases with the initiation of an effective therapy, it is not unusual to detect persistent low-grade uptake in the involved arteries of patients who have normal acute phase reactants (124), which may be due to the persistent inflammatory infiltrates that can be detected in surgical specimens from patients with quiescent disease (110). This fact currently limits the utility of PET in patients' follow-up. These shortcomings have led investigators to explore new ligands for detection of vascular inflammation, such as $\left[{ }^{11} \mathrm{C}\right]-\mathrm{PK} 11195$, which has not been extensively validated yet, but for which promising preliminary result exist (96). MRI imaging can represent an alternative secondline examination, allowing complete evaluation of the aorta and its branches, but appropriate visualization of blood vessel lumen and wall necessitates of dedicated protocols not widely available $(125,126)$. In addition, MRI allows thorough evaluation of the heart, which is frequently involved, albeit sometimes silently, in LVV. The lack of ionizing radiation makes it suitable for repetition in patients follow-up. CT imaging has similar indications to MRI for what concerns blood vessels examination, and is more widely available. It may have a role in the evaluation of coronary arteries involvement in these patients. However, it involves the use of ionizing radiations and nephrotoxic iodinated contrast, which questions its safety for repeated exams in the follow-up of the patients. Current guidelines, while supporting the use of non-invasive imaging in the diagnosis and management of LVV (12), do not give systematic indications its use, deferring the selection of the approach to the practicing physician preferences and local expertize. The use of ultrasonography is well established in the diagnosis of GCA: while a positive ultrasound finding does not replace temporal artery biopsy for the diagnosis, it may provide the definite diagnosis for biopsy negative patients with a strong clinical suspicion for cephalic vessel GCA (127). Ultrasound may thus be the first imaging approach in such patients. FDG-PET, especially if combined with anatomical CT imaging, appears to be particularly appropriate subsequently, as it allows to detect lesions throughout the entire arterial tree (128). PET 


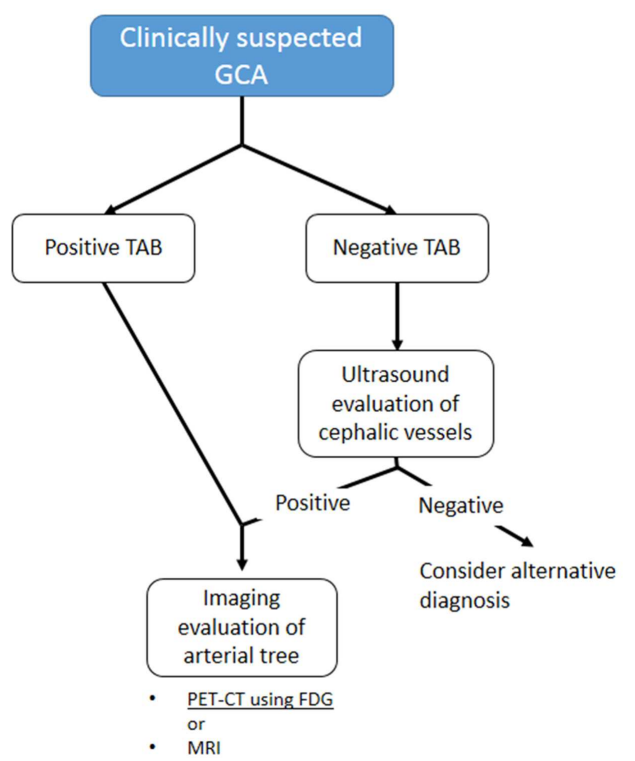

FIGURE 7 | Proposed guidelines-based algorithm for imaging evaluation of patients with large-vessel vasculitis. GCA: giant cell arteritis; TAK: Takayasu arteritis; TAB: temporal artery biopsy. ${ }^{*}$ Atypical presentations for
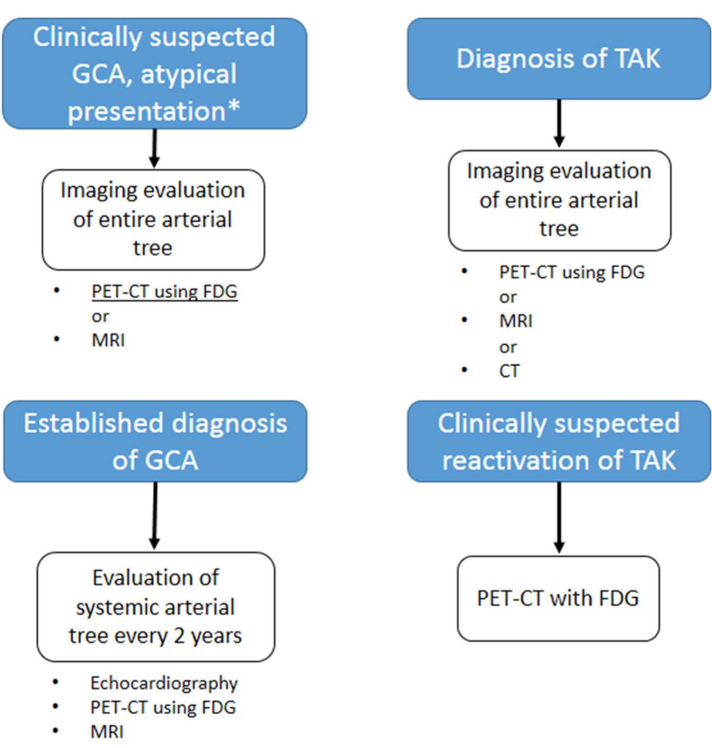

Clinically suspected

reactivation of TAK

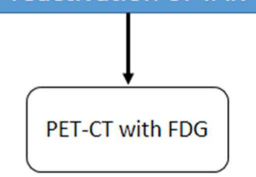

imaging may be particularly appropriate for patients affected by GCA (127) in whom large-vessel involvement and systemic symptoms, e.g., limb claudication, predominate, and in patients with atypical presentation, i.e., fever of unknown origin (122). MRI may have similar indications, although less established. In the subsequent management of the patient, imaging of the arterial tree is recommended every 2 years in order to monitor for lesion progression: echocardiogram for early detection of proximal aortic aneurysm, PET or MRI may be included $(127,129)$. For what concerns TAK, guideline indications are even less precise. A thorough assessment of the arterial tree is currently recommended upon diagnosis, and MRI, PET, and CT are well suited for this purpose (128), while none of these techniques appear to provide a "gold standard" (130). The use of ultrasound is not well established in this disease (131), but it may provide the tool for non-invasive assessment of cephalic vessel, especially carotid artery. The detection of the "halo sign" may provide information on disease activity. One of the major challenges in therapeutic management of TAK is in fact recurrence: even with effective corticosteroid therapy, up to $72 \%$ of the patients experience multiple recurrences within 6 months (119). While no routine imaging follow-up is currently recommended for early detection of recurrence, FDG-PET may be the imaging technique of choice upon clinical suspicion due to its strong correlation with disease activity (132). Diagrams in Figure 7 summarize the suggested imaging approach.

\section{ACKNOWLEDGMENTS}

Enrico Ammirati received financial support from the "Giovane Ricercatore 2009 Grant" from Italian Health Ministry (project code GR-2009-1608780).
GCA include main large-vessel involvement or fever of unknown origin. MRI is a suitable approach only for the former presentation. Currently, no "gold standard" imaging is defined for TAK.

\section{REFERENCES}

1. Jennette JC, Falk RJ, Bacon PA, Basu N, Cid MC, Ferrario F, et al. 2012 Revised international Chapel Hill consensus conference nomenclature of vasculitides. Arthritis Rheum (2013) 65(1):1-11. doi:10.1002/art.37715

2. Miller A, Chan M, Wiik A, Misbah SA, Luqmani RA. An approach to the diagnosis and management of systemic vasculitis. Clin Exp Immunol (2010) 160(2):143-60. doi:10.1111/j.1365-2249.2009.04078.x

3. Pipitone N, Versari A, Hunder GG, Salvarani C. Role of imaging in the diagnosis of large and medium-sized vessel vasculitis. Rheum Dis Clin North Am (2013) 39(3):593-608. doi:10.1016/j.rdc.2013.02.002

4. Weyand CM, Goronzy JJ. Medium- and large-vessel vasculitis. N Engl J Med (2003) 349(2):160-9. doi:10.1056/NEJMra022694

5. Mason JC. Takayasu arteritis - advances in diagnosis and management. Nat Rev Rheumatol (2010) 6(7):406-15. doi:10.1038/nrrheum.2010.82

6. Ishikawa K. Diagnostic approach and proposed criteria for the clinical diagnosis of Takayasu's arteriopathy. J Am Coll Cardiol (1988) 12(4):964-72. doi:10.1016/0735-1097(88)90462-7

7. Arend WP, Michel BA, Bloch DA, Hunder GG, Calabrese LH, Edworthy SM, et al. The American College of Rheumatology 1990 criteria for the classification of Takayasu arteritis. Arthritis Rheum (1990) 33(8):1129-34. doi:10.1002/art.1780330811

8. Hunder GG, Bloch DA, Michel BA, Stevens MB, Arend WP, Calabrese LH, et al. The American College of Rheumatology 1990 criteria for the classification of giant cell arteritis. Arthritis Rheum (1990) 33(8):1122-8. doi:10.1002/art. 1780330810

9. Alibaz-Oner F, Aydin SZ, Direskeneli H. Advances in the diagnosis, assessment and outcome of Takayasu's arteritis. Clin Rheumatol (2013) 32(5):541-6. doi:10.1007/s10067-012-2149-3

10. Smetana GW, Shmerling RH. Does this patient have temporal arteritis? JAMA (2002) 287(1):92-101. doi:10.1001/jama.287.1.92

11. Watts R, Al-Taiar A, Mooney J, Scott D, Macgregor A. The epidemiology of Takayasu arteritis in the UK. Rheumatology (2009) 48(8):1008-11. doi:10.1093/rheumatology/kep153

12. Mukhtyar C, Guillevin L, Cid MC, Dasgupta B, de Groot K, Gross W, et al. EULAR recommendations for the management of large vessel vasculitis. Ann Rheum Dis (2009) 68(3):318-23. doi:10.1136/ard.2008. 088351 
13. Mavrogeni S, Papadopoulos G, Karanasios E, Cokkinos DV. How to image Kawasaki disease: a validation of different imaging techniques. Int J Cardiol (2008) 124(1):27-31. doi:10.1016/j.ijcard.2007.02.035

14. Schmidt WA. Use of imaging studies in the diagnosis of vasculitis. Curr Rheumatol Rep (2004) 6(3):203-11. doi:10.1007/s11926-004-0069-1

15. Numano F. Vasa vasoritis, vasculitis and atherosclerosis. Int J Cardiol (2000) 75(Suppl 1):S1-8. discussion S17-9.

16. Mulligan-Kehoe MJ. The vasa vasorum in diseased and nondiseased arteries. Am J Physiol Heart Circ Physiol (2010) 298(2):H295-305. doi:10.1152/ajpheart. 00884.2009

17. Libby P. Inflammation in atherosclerosis. Arterioscler Thromb Vasc Biol (2012) 32(9):2045-51. doi:10.1161/ATVBAHA.108.179705

18. Libby P, Ridker PM, Maseri A. Inflammation and atherosclerosis. Circulation (2002) 105(9):1135-43. doi:10.1161/hc0902.104353

19. Sanz J, Fayad ZA. Imaging of atherosclerotic cardiovascular disease. Nature (2008) 451(7181):953-7. doi:10.1038/nature06803

20. Skaggs BJ, Hahn BH, McMahon M. Accelerated atherosclerosis in patients with SLE - mechanisms and management. Nat Rev Rheumatol (2012) 8(4):214-23. doi:10.1038/nrrheum.2012.14

21. Gkaliagkousi E, Gavriilaki E, Doumas M, Petidis K, Aslanidis S, Stella D. Cardiovascular risk in rheumatoid arthritis: pathogenesis, diagnosis, and management. J Clin Rheumatol (2012) 18(8):422-30. doi:10.1097/RHU. 0b013e31827846b1

22. Esdaile JM, Abrahamowicz M, Grodzicky T, Li Y, Panaritis C, du Berger R, et al. Traditional Framingham risk factors fail to fully account for accelerated atherosclerosis in systemic lupus erythematosus. Arthritis Rheum (2001) 44(10):2331-7. doi:10.1002/1529-0131(200110)44:10<2331::AID-ART395> 3.0.CO;2-I

23. Camici PG, Rimoldi OE, Gaemperli O, Libby P. Non-invasive anatomic and functional imaging of vascular inflammation and unstable plaque. Eur Heart $J$ (2012) 33(11):1309-17. doi:10.1093/eurheartj/ehs067

24. Ammirati E, Magnoni M, Camici PG. Need for new non-invasive imaging strategies to identify high-risk asymptomatic patients with carotid stenosis. Int J Cardiol (2013) 168(4):4342-3. doi:10.1016/j.ijcard.2013.05.079

25. Schmidt WA, Gromnica-Ihle E. What is the best approach to diagnosing large-vessel vasculitis? Best Pract Res Clin Rheumatol (2005) 19(2):223-42. doi:10.1016/j.berh.2005.01.006

26. Schmidt WA, Backhaus M. What the practising rheumatologist needs to know about the technical fundamentals of ultrasonography. Best Pract Res Clin Rheumatol (2008) 22(6):981-99. doi:10.1016/j.berh.2008.09.013

27. Zierler RE, Beach KW, Bergelin RO, Lal BK, Moore WS, Roubin GS, et al. Agreement between site-reported and ultrasound core laboratory results for duplex ultrasound velocity measurements in the carotid revascularization endarterectomy versus stenting trial. J Vasc Surg (2014) 59(1):2-7. doi:10.1016/j.jvs.2013. 06.071

28. De Miguel E, Castillo C, Rodriguez A, De Agustin JJ; Working Group Ultrasound Giant Cell Arteritis. Learning and reliability of colour Doppler ultrasound in giant cell arteritis. Clin Exp Rheumatol (2009) 27(1 Suppl 52):S53-8.

29. Schmidt WA, Kraft HE, Vorpahl K, Volker L, Gromnica-Ihle EJ. Color duplex ultrasonography in the diagnosis of temporal arteritis. N Engl J Med (1997) 337(19):1336-42. doi:10.1056/NEJM199711063371902

30. Karassa FB, Matsagas MI, Schmidt WA, Ioannidis JP. Meta-analysis: test performance of ultrasonography for giant-cell arteritis. Ann Intern Med (2005) 142(5):359-69. doi:10.7326/0003-4819-142-5-200503010-00011

31. Arida A, Kyprianou M, Kanakis M, Sfikakis PP. The diagnostic value of ultrasonography-derived edema of the temporal artery wall in giant cell arteritis: a second meta-analysis. BMC Musculoskelet Disord (2010) 11:44. doi:10.1186/1471-2474-11-44

32. Ball EL, Walsh SR, Tang TY, Gohil R, Clarke JM. Role of ultrasonography in the diagnosis of temporal arteritis. Br J Surg (2010) 97(12):1765-71. doi:10.1002/bjs.7252

33. Ghinoi A, Pipitone N, Nicolini A, Boiardi L, Silingardi M, Germano G, et al. Large-vessel involvement in recent-onset giant cell arteritis: a casecontrol colour-Doppler sonography study. Rheumatology (2012) 51(4):730-4. doi:10.1093/rheumatology/ker329

34. Aschwanden M, Kesten F, Stern M, Thalhammer C, Walker UA, Tyndall A, et al. Vascular involvement in patients with giant cell arteritis determined by duplex sonography of 2x11 arterial regions. Ann Rheum Dis (2010) 69(7):1356-9. doi:10.1136/ard.2009.122135
35. Diamantopoulos AP, Haugeberg G, Hetland H, Soldal DM, Bie R, Myklebust G. Diagnostic value of color Doppler ultrasonography of temporal arteries and large vessels in giant cell arteritis: a consecutive case series. Arthritis Care Res (Hoboken) (2014) 66(1):113-9. doi:10.1002/acr.22178

36. Schmidt WA, Seifert A, Gromnica-Ihle E, Krause A, Natusch A. Ultrasound of proximal upper extremity arteries to increase the diagnostic yield in largevessel giant cell arteritis. Rheumatology (2008) 47(1):96-101. doi:10.1093/ rheumatology/kem322

37. Maeda H, Handa N, Matsumoto M, Hougaku H, Ogawa S, Oku N, et al. Carotid lesions detected by B-mode ultrasonography in Takayasu's arteritis: "macaroni sign" as an indicator of the disease. Ultrasound Med Biol (1991) 17(7):695-701. doi:10.1016/0301-5629(91)90101-2

38. Reinhard M, Schmidt D, Hetzel A. Color-coded sonography in suspected temporal arteritis-experiences after 83 cases. Rheumatol Int (2004) 24(6):340-6. doi:10.1007/s00296-003-0372-6

39. Habib HM, Essa AA, Hassan AA. Color duplex ultrasonography of temporal arteries: role in diagnosis and follow-up of suspected cases of temporal arteritis. Clin Rheumatol (2012) 31(2):231-7. doi:10.1007/s10067-011-1808-0

40. Keo HH, Caliezi G, Baumgartner I, Diehm N, Willenberg T. Increasing echogenicity of diffuse circumferential thickening ("macaroni sign") of the carotid artery wall with decreasing inflammatory activity of Takayasu arteritis. J Clin Ultrasound (2013) 41(1):59-62. doi:10.1002/jcu.20894

41. Nambi V, Chambless L, Folsom AR, He M, Hu Y, Mosley T, et al. Carotid intimamedia thickness and presence or absence of plaque improves prediction of coronary heart disease risk: the ARIC (atherosclerosis risk in communities) study. J Am Coll Cardiol (2010) 55(15):1600-7. doi:10.1016/S0735-1097(10) 61285-5

42. Tyrrell PN, Beyene J, Feldman BM, McCrindle BW, Silverman ED, Bradley TJ. Rheumatic disease and carotid intima-media thickness: a systematic review and meta-analysis. Arterioscler Thromb Vasc Biol (2010) 30(5):1014-26. doi:10.1161/ATVBAHA.109.198424

43. Ammirati E, Bozzolo EP, Contri R, Baragetti A, Palini AG, Cianflone D, et al. Cardiometabolic and immune factors associated with increased common carotid artery intima media thickness and cardiovascular disease in patients with systemic lupus erythematosus. Nutr Metab Cardiovasc Dis (2014) 24(7):751-9. doi:10.1016/j.numecd.2014.01.006

44. de Jong N, Bouakaz A, Frinking P. Basic acoustic properties of microbubbles. Echocardiography (2002) 19(3):229-40. doi:10.1046/j.1540-8175.2002.00229.x

45. Kono Y, Pinnell SP, Sirlin CB, Sparks SR, Georgy B, Wong W, et al. Carotid arteries: contrast-enhanced US angiography - preliminary clinical experience. Radiology (2004) 230(2):561-8. doi:10.1148/radiol.2302020318

46. Coli S, Magnoni M, Sangiorgi G, Marrocco-Trischitta MM, Melisurgo G, Mauriello A, et al. Contrast-enhanced ultrasound imaging of intraplaque neovascularization in carotid arteries: correlation with histology and plaque echogenicity. J Am Coll Cardiol (2008) 52(3):223-30. doi:10.1016/j.jacc.2008.02.082

47. Virmani R, Kolodgie FD, Burke AP, Finn AV, Gold HK, Tulenko TN, et al. Atherosclerotic plaque progression and vulnerability to rupture: angiogenesis as a source of intraplaque hemorrhage. Arterioscler Thromb Vasc Biol (2005) 25(10):2054-61. doi:10.1161/01.ATV.0000178991.71605.18

48. Giordana P, Baque-Juston MC, Jeandel PY, Mondot L, Hirlemann J, Padovani B, et al. Contrast-enhanced ultrasound of carotid artery wall in Takayasu disease: first evidence of application in diagnosis and monitoring of response to treatment. Circulation (2011) 124(2):245-7. doi:10.1161/CIRCULATIONAHA 110.006668

49. Magnoni M, Dagna L, Coli S, Cianflone D, Sabbadini MG, Maseri A. Assessment of Takayasu arteritis activity by carotid contrast-enhanced ultrasound. Circ Cardiovasc Imaging (2011) 4(2):e1-2. doi:10.1161/CIRCIMAGING.110. 960906

50. Schinkel AF, van den Oord SC, van der Steen AF, van Laar JA, Sijbrands EJ. Utility of contrast-enhanced ultrasound for the assessment of the carotid artery wall in patients with Takayasu or giant cell arteritis. Eur Heart J Cardiovasc Imaging (2013) 15(5):541-6. doi:10.1093/ehjci/jet243

51. Villanueva FS. Molecular imaging of cardiovascular disease using ultrasound. J Nucl Cardiol (2008) 15(4):576-86. doi:10.1016/j.nuclcard.2008.05.005

52. Villanueva FS, Wagner WR. Ultrasound molecular imaging of cardiovascular disease. Nat Clin Pract Cardiovasc Med (2008) 5(Suppl 2):S26-32. doi:10.1038/ncpcardio1246

53. Barger AC, Beeuwkes R III, Lainey LL, Silverman KJ. Hypothesis: vasa vasorum and neovascularization of human coronary arteries. A possible role in 
the pathophysiology of atherosclerosis. N Engl J Med (1984) 310(3):175-7. doi:10.1056/NEJM198401193100307

54. Kolodgie FD, Gold HK, Burke AP, Fowler DR, Kruth HS, Weber DK, et al. Intraplaque hemorrhage and progression of coronary atheroma. $N$ Engl J Med (2003) 349(24):2316-25. doi:10.1056/NEJMoa035655

55. Shah F, Balan P, Weinberg M, Reddy V, Neems R, Feinstein M, et al. Contrastenhanced ultrasound imaging of atherosclerotic carotid plaque neovascularization: a new surrogate marker of atherosclerosis? Vasc Med (2007) 12(4):291-7. doi:10.1177/1358863X07083363

56. Prabhu M, Raju D, Pauli H. Transesophageal echocardiography: instrumentation and system controls. Ann Card Anaesth (2012) 15(2):144-55. doi:10.4103/ 0971-9784.95080

57. Moortgat S, Tuerlinckx D, Bodart E, El Khoury G, Moniotte S. Severe ostial stenosis of the left coronary artery in a 12-year-old girl as the first manifestation of Takayasu's arteritis. Acta Cardiol (2009) 64(6):825-9. doi:10.2143/AC. 64.6.2044753

58. Kopterides P, Moyssakis I, Margos P, Sipsas NV. Echocardiographic findings in patients with temporal arteritis: apropos of one case of temporal arteritisassociated verrucous (Libman-Sachs) endocarditis. Clin Exp Rheumatol (2006) 24(2 Suppl 41):S35-7.

59. Nakao M, Ong KK, Lim YP, Wong KY. Aortic intimal fold in Takayasu arteritis causing obstruction of left coronary ostium. Pediatr Cardiol (2011) 32(7):990-2. doi:10.1007/s00246-011-0023-8

60. Bezerra Lira-Filho E, Campos O, Lazaro Andrade J, Henrique Fischer C, Godoy Nunes C, Cavalcanti Lins A, et al. Thoracic aorta evaluation in patients with Takayasu's arteritis by transesophageal echocardiography. J Am Soc Echocar$\operatorname{diogr}(2006)$ 19(6):829-34. doi:10.1016/j.echo.2005.12.023

61. Espinola-Zavaleta N, Soto ME, Bauk L, Miguel Casanova J, Keirns C, Avila Vanzzini N, et al. Coronary reserve in Takayasu's arteritis: transesophageal echocardiographic analysis. Echocardiography (2005) 22(7):593-8. doi:10. 1111/j.1540-8175.2005.40105.x

62. Valente F, Carro A, Moral S, Evangelista A. Multiple thrombi in the ascending aorta usefulness of contrast transesophageal echocardiography in a case of Horton's aortitis. Circulation (2013) 128(3):e44-5. doi:10.1161/ CIRCULATIONAHA.112.001156

63. Kissin EY, Merkel PA. Diagnostic imaging in Takayasu arteritis. Curr Opin Rheumatol (2004) 16(1):31-7. doi:10.1097/00002281-200401000-00007

64. Gotway MB, Araoz PA, Macedo TA, Stanson AW, Higgins CB, Ring EJ, et al. Imaging findings in Takayasu's arteritis. Am J Roentgenol (2005) 184(6):1945-50. doi:10.2214/ajr.184.6.01841945

65. Khandelwal N, Kalra N, Garg MK, Kang M, Lal A, Jain S, et al. Multidetector CT angiography in Takayasu arteritis. Eur J Radiol (2011) 77(2):369-74. doi:10.1016/j.ejrad.2009.08.001

66. Yoshida S, Akiba H, Tamakawa M, Yama N, Takeda M, Hareyama M, et al. The spectrum of findings in supra-aortic Takayasu's arteritis as seen on spiral CT angiography and digital subtraction angiography. Cardiovasc Intervent Radiol (2001) 24(2):117-21. doi:10.1007/s002700000368

67. Matsunaga N, Hayashi K, Sakamoto I, Ogawa Y, Matsumoto T. Takayasu arteritis: protean radiologic manifestations and diagnosis. Radiographics (1997) 17(3):579-94. doi:10.1148/radiographics.17.3.9153698

68. Park JH, Chung JW, Im JG, Kim SK, Park YB, Han MC. Takayasu arteritis: evaluation of mural changes in the aorta and pulmonary artery with CT angiography. Radiology (1995) 196(1):89-93. doi:10.1148/radiology.196.1.7784596

69. Chung JW, Kim HC, Choi YH, Kim SJ, Lee W, Park JH. Patterns of aortic involvement in Takayasu arteritis and its clinical implications: evaluation with spiral computed tomography angiography. J Vasc Surg (2007) 45(5):906-14. doi:10.1016/j.jvs.2007.01.016

70. Paul JF, Fiessinger JN, Sapoval M, Hernigou A, Mousseaux E, Emmerich J, et al. Follow-up electron beam CT for the management of early phase Takayasu arteritis. J Comput Assist Tomogr (2001) 25(6):924-31. doi:10.1097/00004728200111000-00015

71. Yamada I, Nakagawa T, Himeno Y, Numano F, Shibuya H. Takayasu arteritis: evaluation of the thoracic aorta with CT angiography. Radiology (1998) 209(1):103-9. doi:10.1148/radiology.209.1.9769819

72. Kang EJ, Kim SM, Choe YH, Lee GY, Lee KN, Kim DK. Takayasu arteritis: assessment of coronary arterial abnormalities with 128 -section dual-source CT angiography of the coronary arteries and aorta. Radiology (2014) 270(1):74-81. doi:10.1148/radiol.13122195
73. Prieto-Gonzalèz S, Arguis P, Garcia-Martinez A, Espigol-Frigole G, TaveraBahillo I, Butjosa M, et al. Large vessel involvement in biopsy-proven giant cell arteritis: prospective study in 40 newly diagnosed patients using CT angiography. Ann Rheum Dis (2012) 71(7):1170-6. doi:10.1136/annrheumdis-2011200865

74. Weber DA, Ivanovic M. Correlative image registration. Semin Nucl Med (1994) 24(4):311-23. doi:10.1016/S0001-2998(05)80021-2

75. Gaemperli O, Boyle JJ, Rimoldi OE, Mason JC, Camici PG. Molecular imaging of vascular inflammation. Eur J Nucl Med Mol Imaging (2010) 37(6):1236. doi:10.1007/s00259-009-1371-y

76. Weber WA, Grosu AL, Czernin J. Technology insight: advances in molecular imaging and an appraisal of PET/CT scanning. Nat Clin Pract Oncol (2008) 5(3):160-70. doi:10.1038/ncponc1041

77. Ishimori T, Saga T, Mamede M, Kobayashi H, Higashi T, Nakamoto Y, et al. Increased (18)F-FDG uptake in a model of inflammation: concanavalin Amediated lymphocyte activation. J Nucl Med (2002) 43(5):658-63.

78. Meller J, Strutz F, Siefker U, Scheel A, Sahlmann CO, Lehmann K, et al. Early diagnosis and follow-up of aortitis with [(18)F]FDG PET and MRI. Eur J Nucl Med Mol Imaging (2003) 30(5):730-6. doi:10.1007/s00259-003-1144-y

79. Belhocine T, Blockmans D, Hustinx R, Vandevivere J, Mortelmans L. Imaging of large vessel vasculitis with (18)FDG PET: illusion or reality? A critical review of the literature data. Eur J Nucl Med Mol Imaging (2003) 30(9):1305-13. doi:10.1007/s00259-003-1209-y

80. Hautzel H, Sander O, Heinzel A, Schneider M, Muller HW. Assessment of large-vessel involvement in giant cell arteritis with 18F-FDG PET: introducing an ROC-analysis-based cutoff ratio. J Nucl Med (2008) 49(7):1107-13. doi:10.2967/jnumed.108.051920

81. Besson FL, Parienti JJ, Bienvenu B, Prior JO, Costo S, Bouvard G, et al. Diagnostic performance of (1)(8)F-fluorodeoxyglucose positron emission tomography in giant cell arteritis: a systematic review and meta-analysis. Eur J Nucl Med Mol Imaging (2011) 38(9):1764-72. doi:10.1007/s00259-011-1830-0

82. Lehmann P, Buchtala S, Achajew N, Haerle P, Ehrenstein B, Lighvani H, et al. 18F-FDG PET as a diagnostic procedure in large vessel vasculitis-a controlled, blinded re-examination of routine PET scans. Clin Rheumatol (2011) 30(1):37-42. doi:10.1007/s10067-010-1598-9

83. Walter MA. [(18)F]fluorodeoxyglucose PET in large vessel vasculitis. Radiol Clin North Am (2007) 45(4):735-44, viii. doi:10.1016/j.rcl.2007.05.012

84. Henes JC, Muller M, Krieger J, Balletshofer B, Pfannenberg AC, Kanz L, et al. [18F] FDG-PET/CT as a new and sensitive imaging method for the diagnosis of large vessel vasculitis. Clin Exp Rheumatol (2008) 26(3 Suppl 49): S47-52.

85. Kobayashi $Y$, Ishii K, Oda K, Nariai T, Tanaka Y, Ishiwata K, et al. Aortic wall inflammation due to Takayasu arteritis imaged with 18 F-FDG PET coregistered with enhanced CT. J Nucl Med (2005) 46(6):917-22.

86. Rehak Z, Szturz P, Kren L, Fojtik Z, Stanicek J. Upsampling from aorta and aortic branches: PET/CT hybrid imaging identified 18F-FDG hypermetabolism in inflamed temporal and occipital arteries. Clin Nucl Med (2014) 39(1):e84-6. doi:10.1097/RLU.0b013e3182868aae

87. Fuchs M, Briel M, Daikeler T, Walker UA, Rasch H, Berg S, et al. The impact of 18F-FDG PET on the management of patients with suspected large vessel vasculitis. Eur J Nucl Med Mol Imaging (2012) 39(2):344-53. doi:10.1007/s00259-011-1967-x

88. Blockmans D, de Ceuninck L, Vanderschueren S, Knockaert D, Mortelmans L, Bobbaers $\mathrm{H}$. Repetitive 18F-fluorodeoxyglucose positron emission tomography in giant cell arteritis: a prospective study of 35 patients. Arthritis Rheum (2006) 55(1):131-7. doi:10.1002/art.21699

89. Cheng Y, Lv N, Wang Z, Chen B, Dang A. 18-FDG-PET in assessing disease activity in Takayasu arteritis: a meta-analysis. Clin Exp Rheumatol (2013) 31(1 Suppl 75):S22-7.

90. Blockmans D, Coudyzer W, Vanderschueren S, Stroobants S, Loeckx D, Heye S, et al. Relationship between fluorodeoxyglucose uptake in the large vessels and late aortic diameter in giant cell arteritis. Rheumatology (2008) 47(8):1179-84. doi:10.1093/rheumatology/ken119

91. Papadopoulos V, Baraldi M, Guilarte TR, Knudsen TB, Lacapere JJ, Lindemann $\mathrm{P}$, et al. Translocator protein $(18 \mathrm{kDa})$ : new nomenclature for the peripheral-type benzodiazepine receptor based on its structure and molecular function. Trends Pharmacol Sci (2006) 27(8):402-9. doi:10.1016/ j.tips.2006.06.005 
92. Canat X, Carayon P, Bouaboula M, Cahard D, Shire D, Roque C, et al. Distribution profile and properties of peripheral-type benzodiazepine receptors on human hemopoietic cells. Life Sci (1993) 52(1):107-18.

93. Canat X, Guillaumont A, Bouaboula M, Poinot-Chazel C, Derocq JM, Carayon $\mathrm{P}$, et al. Peripheral benzodiazepine receptor modulation with phagocyte differentiation. Biochem Pharmacol (1993) 46(3):551-4. doi:10.1016/0006-2952(93) 90535-5

94. Cagnin A, Kassiou M, Meikle SR, Banati RB. Positron emission tomography imaging of neuroinflammation. Neurotherapeutics (2007) 4(3):443-52. doi:10.1016/j.nurt.2007.04.006

95. van der Laken CJ, Elzinga EH, Kropholler MA, Molthoff CF, van der Heijden JW, Maruyama K, et al. Noninvasive imaging of macrophages in rheumatoid synovitis using 11C-(R)-PK11195 and positron emission tomography. Arthritis Rheum (2008) 58(11):3350-5. doi:10.1002/art.23955

96. Pugliese F, Gaemperli O, Kinderlerer AR, Lamare F, Shalhoub J, Davies AH, et al. Imaging of vascular inflammation with [11C]-PK11195 and positron emission tomography/computed tomography angiography. J Am Coll Cardiol (2010) 56(8):653-61. doi:10.1016/j.jacc.2010.02.063

97. Lamare F, Hinz R, Gaemperli O, Pugliese F, Mason JC, Spinks T, et al. Detection and quantification of large-vessel inflammation with 11C-(R)-PK11195 PET/CT. J Nucl Med (2011) 52(1):33-9. doi:10.2967/jnumed.110.079038

98. Einstein AJ, Moser KW, Thompson RC, Cerqueira MD, Henzlova MJ. Radiation dose to patients from cardiac diagnostic imaging. Circulation (2007) 116(11):1290-305. doi:10.1161/CIRCULATIONAHA.107.688101

99. Gaemperli O, Shalhoub J, Owen DR, Lamare F, Johansson S, Fouladi N, et al. Imaging intraplaque inflammation in carotid atherosclerosis with $11 \mathrm{C}$ PK11195 positron emission tomography/computed tomography. Eur Heart J (2012) 33(15):1902-10. doi:10.1093/eurheartj/ehr367

100. Wang Y, Yue X, Kiesewetter DO, Niu G, Teng G, Chen X. PET imaging of neuroinflammation in a rat traumatic brain injury model with radiolabeled TSPO ligand DPA-714. Eur J Nucl Med Mol Imaging (2014) 41(7):1440-9. doi:10.1007/s00259-014-2727-5

101. Raman SV, Aneja A, Jarjour WN. CMR in inflammatory vasculitis. J Cardiovasc Magn Reson (2012) 14:82. doi:10.1186/1532-429X-14-82

102. Mavrogeni S, Cantini F, Pohost GM. Systemic vasculitis: an underestimated cause of heart failure - assessment by cardiovascular magnetic resonance. Rev Cardiovasc Med (2013) 14(1):49-55.

103. Simonetti OP, Finn JP, White RD, Laub G, Henry DA. "Black blood" T2weighted inversion-recovery MR imaging of the heart. Radiology (1996) 199(1):49-57.

104. Hartung MP, Grist TM, Francois CJ. Magnetic resonance angiography: current status and future directions. J Cardiovasc Magn Reson (2011) 13:19. doi:10.1186/1532-429X-13-19

105. Piccini D, Monney P, Sierro C, Coppo S, Bonanno G, van Heeswijk RB, et al. Respiratory self-navigated postcontrast whole-heart coronary MR angiography: initial experience in patients. Radiology (2014) 270(2):378-86. doi:10. 1148/radiol.13132045

106. Mavrogeni S, Papadopoulos G, Douskou M, Kaklis S, Seimenis I, Baras P, et al. Magnetic resonance angiography is equivalent to X-ray coronary angiography for the evaluation of coronary arteries in Kawasaki disease. J Am Coll Cardiol (2004) 43(4):649-52. doi:10.1016/j.jacc.2003.08.052

107. Mavrogeni S, Bratis K, Karanasios E, Georgakopoulos D, Kaklis S, Varlamis $\mathrm{G}$, et al. CMR evaluation of cardiac involvement during the convalescence of Kawasaki disease. JACC Cardiovasc Imaging (2011) 4(10):1140-1. doi:10.1016/j.jcmg.2011.04.021

108. Roghi A, Pedrotti P, Milazzo A, Vignati G, Martinelli L, Paino R, et al. Acute myocardial infarction and cardiac arrest in atypical Takayasu aortitis in a young girl: unusual diagnostic role of cardiac magnetic resonance imaging in emergency setting. Circulation (2010) 121(14):e370-5. doi:10.1161/CIR. 0b013e3181dab9ee

109. Kerr GS, Hallahan CW, Giordano J, Leavitt RY, Fauci AS, Rottem M, et al. Takayasu arteritis. Ann Intern Med (1994) 120(11):919-29. doi:10.7326/00034819-120-11-199406010-00004

110. Lagneau P, Michel JB, Vuong PN. Surgical treatment of Takayasu's disease. Ann Surg (1987) 205(2):157-66. doi:10.1097/00000658-198702000-00010

111. Hoffman GS, Ahmed AE. Surrogate markers of disease activity in patients with Takayasu arteritis. A preliminary report from The International Network for the Study of the Systemic Vasculitides (INSSYS). Int J Cardiol (1998) 66(Suppl 1):S191-4; discussion S5. doi:10.1016/S0167-5273(98)00181-8
112. Bonacina F, Baragetti A, Catapano AL, Norata GD. Long pentraxin 3: experimental and clinical relevance in cardiovascular diseases. Mediators Inflamm (2013) 2013:725102. doi:10.1155/2013/725102

113. Dagna L, Salvo F, Tiraboschi M, Bozzolo EP, Franchini S, Doglioni C, et al. Pentraxin-3 as a marker of disease activity in Takayasu arteritis. Ann Intern Med (2011) 155(7):425-33. doi:10.7326/0003-4819-155-7-201110040-00005

114. Ishihara T, Haraguchi G, Kamiishi T, Tezuka D, Inagaki H, Isobe M. Sensitive assessment of activity of Takayasu's arteritis by pentraxin3, a new biomarker. J Am Coll Cardiol (2011) 57(16):1712-3. doi:10.1016/j.jacc.2010.10.058

115. Ishihara T, Haraguchi G, Tezuka D, Kamiishi T, Inagaki H, Isobe M. Diagnosis and assessment of Takayasu arteritis by multiple biomarkers. Circ J (2013) 77(2):477-83. doi:10.1253/circj.CJ-12-0131

116. Schmidt WA, Moll A, Seifert A, Schicke B, Gromnica-Ihle E, Krause A. Prognosis of large-vessel giant cell arteritis. Rheumatology (2008) 47(9):1406-8. doi:10.1093/rheumatology/ken258

117. Hauenstein C, Reinhard M, Geiger J, Markl M, Hetzel A, Treszl A, et al. Effects of early corticosteroid treatment on magnetic resonance imaging and ultrasonography findings in giant cell arteritis. Rheumatology (2012) 51(11):1999-2003 doi:10.1093/rheumatology/kes153

118. Park MC, Lee SW, Park YB, Chung NS, Lee SK. Clinical characteristics and outcomes of Takayasu's arteritis: analysis of 108 patients using standardized criteria for diagnosis, activity assessment, and angiographic classification. Scand J Rheumatol (2005) 34(4):284-92. doi:10.1080/03009740510026526

119. Maksimowicz-McKinnon K, Clark TM, Hoffman GS. Limitations of therapy and a guarded prognosis in an American cohort of Takayasu arteritis patients. Arthritis Rheum (2007) 56(3):1000-9. doi:10.1002/art.22404

120. Salvarani C, Silingardi M, Ghirarduzzi A, Lo Scocco G, Macchioni P, Bajocchi $\mathrm{G}$, et al. Is duplex ultrasonography useful for the diagnosis of giant-cell arteritis? Ann Intern Med (2002) 137(4):232-8. doi:10.7326/0003-4819-1374-200208200-00006

121. Seth S, Goyal NK, Jagia P, Gulati G, Karthikeyan G, Sharma S, et al. Carotid intima-medial thickness as a marker of disease activity in Takayasu's arteritis. Int J Cardiol (2006) 108(3):385-90.

122. Meller J, Sahlmann CO, Scheel AK. 18F-FDG PET and PET/CT in fever of unknown origin. J Nucl Med (2007) 48(1):35-45.

123. Janssen SP, Comans EH, Voskuyl AE, Wisselink W, Smulders YM. Giant cell arteritis: heterogeneity in clinical presentation and imaging results. J Vasc Surg (2008) 48(4):1025-31. doi:10.1016/j.jvs.2008.04.054

124. Arnaud L, Haroche J, Malek Z, Archambaud F, Gambotti L, Grimon G, et al. Is (18)F-fluorodeoxyglucose positron emission tomography scanning a reliable way to assess disease activity in Takayasu arteritis? Arthritis Rheum (2009) 60(4):1193-200. doi:10.1002/art.24416

125. Steeds RP, Mohiaddin R. Takayasu arteritis: role of cardiovascular magnetic imaging. Int J Cardiol (2006) 109(1):1-6. doi:10.1016/j.ijcard.2004.09.023

126. Andrews J, Mason JC. Takayasu's arteritis - recent advances in imaging offer promise. Rheumatology (2007) 46(1):6-15. doi:10.1093/rheumatology/kel323

127. Dasgupta B. Concise guidance: diagnosis and management of giant cell arteritis. Clin Med (2010) 10(4):381-6. doi:10.7861/clinmedicine.10-3-270

128. Japanese Circulation Society. Guideline for management of vasculitis syndrome (JCS 2008). Japanese Circulation Society. Circ J (2011) 75(2):474-503. doi:10.1253/circj.CJ-88-0007

129. Dasgupta B, Borg FA, Hassan N, Alexander L, Barraclough K, Bourke B, et al. BSR and BHPR guidelines for the management of giant cell arteritis. Rheumatology (2010) 49(8):1594-7. doi:10.1093/rheumatology/keq039a

130. Direskeneli H, Aydin SZ, Merkel PA. Assessment of disease activity and progression in Takayasu's arteritis. Clin Exp Rheumatol (2011) 29(1 Suppl 64):S86-91.

131. Borg FA, Dasgupta B. Treatment and outcomes of large vessel arteritis. Best Pract Res Clin Rheumatol (2009) 23(3):325-37. doi:10.1016/j.berh.2009. 04.001

132. Tezuka D, Haraguchi G, Ishihara T, Ohigashi H, Inagaki H, Suzuki J, et al. Role of FDG PET-CT in Takayasu arteritis: sensitive detection of recurrences. JACC Cardiovasc Imaging (2012) 5(4):422-9. doi:10.1016/j.jcmg.2012.01.013

133. Comarmond C, Cluzel P, Toledano D, Costedoat-Chalumeau N, Isnard R, Gaudric J, et al. Findings of cardiac magnetic resonance imaging in asymptomatic myocardial ischemic disease in Takayasu arteritis. Am J Cardiol (2014) 113(5):881-7. doi:10.1016/j.amjcard.2013.11.045

134. Li D, Lin J, Yan F. Detecting disease extent and activity of Takayasu arteritis using whole-body magnetic resonance angiography and vessel wall imaging as 
a 1-stop solution. J Comput Assist Tomogr (2011) 35(4):468-74. doi:10.1097/ RCT.0b013e318222d698

135. Koenigkam-Santos M, Sharma P, Kalb B, Oshinski JN, Weyand CM, Goronzy JJ, et al. Magnetic resonance angiography in extracranial giant cell arteritis. J Clin Rheumatol (2011) 17(6):306-10. doi:10.1097/RHU.0b013e31822acec6

136. Mavrogeni S, Karabela G, Gialafos E, Stavropoulos E, Spiliotis G, Katsifis G, et al. Cardiac involvement in ANCA (+) and ANCA ( - ) Churg-Strauss syndrome evaluated by cardiovascular magnetic resonance. Inflamm Allergy Drug Targets (2013) 12(5):322-7.

Conflict of Interest Statement: The authors declare that the research was conducted in the absence of any commercial or financial relationships that could be construed as a potential conflict of interest.
Received: 29 May 2014; paper pending published: 19 June 2014; accepted: 05 August 2014; published online: 18 August 2014.

Citation: Ammirati E, Moroni F, Pedrotti P, Scotti I, Magnoni M, Bozzolo EP, Rimoldi $O E$ and Camici PG (2014) Non-invasive imaging of vascular inflammation. Front. Immunol. 5:399. doi: 10.3389/fimmu.2014.00399

This article was submitted to Inflammation, a section of the journal Frontiers in Immunology.

Copyright (C) 2014 Ammirati, Moroni, Pedrotti, Scotti, Magnoni, Bozzolo, Rimoldi and Camici. This is an open-access article distributed under the terms of the Creative Commons Attribution License (CC BY). The use, distribution or reproduction in other forums is permitted, provided the original author(s) or licensor are credited and that the original publication in this journal is cited, in accordance with accepted academic practice. No use, distribution or reproduction is permitted which does not comply with these terms. 